\title{
Nanocatalysts promote Streptococcus mutans biofilm matrix degradation and enhance bacterial killing to suppress dental caries in vivo
}

\author{
Lizeng Gao ${ }^{1,2 *}$, Yuan Liu ${ }^{1}$, Dongyeop Kim ${ }^{1}$, Yong Li ${ }^{1}$, Geelsu Hwang ${ }^{1}$, Pratap C. Naha ${ }^{3}$, \\ David P. Cormode ${ }^{3,4}$, Hyun Koo ${ }^{1,2 *}$
}

${ }^{1}$ Biofilm Research Labs, Levy Center for Oral Health, School of Dental Medicine, University of Pennsylvania, Philadelphia, PA, USA

${ }^{2}$ Department of Orthodontics and Divisions of Pediatric Dentistry \& Community Oral Health, School of Dental Medicine, University of Pennsylvania, Philadelphia, PA, USA

${ }^{3}$ Department of Radiology, Perelman School of Medicine, University of Pennsylvania, Philadelphia, PA, USA

${ }^{4}$ Department of Bioengineering, School of Engineering and Applied Sciences, University of Pennsylvania, Philadelphia, PA, USA

* Corresponding authors:

Hyun Koo, University of Pennsylvania, School of Dental Medicine, 240 South 40 th Street, Levy Bldg. Rm 417, Philadelphia, PA 19104, Tel: (215) 898-8993; E-mail: koohy@ dental.upenn.edu; Lizeng Gao, Current address: Yangzhou University, School of Medicine, 11 Huaihai Road, Yangzhou, Jiangsu, China 225001, Tel: +86 -514-87797090; E-mail: lzgao@yzu.edu.cn 
Keywords: catalysis, iron oxide, nanoparticles, biofilms, extracellular matrix, antibacterial, dental caries 


\section{Introduction}

Biofilms consist of highly organized clusters of bacterial cells that are firmly adherent to surfaces and enmeshed in a 3D matrix of extracellular polymeric substances, such as exopolysaccharides (EPS) [1,2]. Many infectious diseases in humans are caused by biofilms [13]. Dental caries (tooth decay) is one of the most prevalent and costly biofilm-dependent oral diseases [4-6]. Caries-causing biofilms (or plaque) develop when virulent species, such as Streptococcus mutans and other bacteria, utilize dietary sugars to accumulate on tooth surface through EPS production, and acidify the local environment $[4,5]$. S. mutans has been considered a key modulator in the disease process because it is the primary EPS producer in oral cavity, while being both acidogenic and aciduric [4]. The pathogens embedded in the EPS-rich matrix persist and produce highly acidic niches with $\mathrm{pH}$ values close to 4.5 , which erode the enamelapatite on teeth and leads to the onset of dental caries [4-6]. The presence of extracellular matrix, with its local barriers and altered microenvironment reduces drug access, triggers bacterial tolerance to antimicrobials while enhancing the mechanical stability of the biofilms, making them difficult to treat or remove $[2,3,4,7]$. Thus, novel approaches with enhanced efficacy at acidic $\mathrm{pH}$ values that could both disrupt the matrix and at the same time kill the bacteria embedded within plaque-biofilms would be highly desirable [8, 9].

Current approaches against caries-causing (cariogenic) plaque-biofilm are restricted to conventional antimicrobials, including chlorhexidine $(\mathrm{CHX})$, hydrogen peroxide and other chemical biocides that are incapable of degrading the EPS matrix or reducing enamel aciddissolution. Among them, $\mathrm{CHX}$ is considered the 'gold standard' oral antimicrobial agent [10, 11]. Although capable of killing bacterial pathogens in the planktonic state, CHX is far less effective against plaque-biofilms, does not prevent caries and is not suitable for daily use due to 
adverse effects, including tartar formation and tooth staining [10, 11]. Antimicrobial nanomaterials or nanoparticles provide a promising strategy to combat biofilm initiation by reducing bacterial viability and bacterial adhesion of pre-treated surfaces $[8,9,12]$. However, their biological activity is mostly restricted to antibacterial effects rather than causing matrix disruption, resulting in limited effectiveness once the biofilm is formed and the bacteria are protected by the surrounding milieu. Fluoride, the mainstay of caries prevention, does not offer complete disease protection [13-15]. Fluoride exerts its major effect by enhancing remineralization and reducing tooth enamel demineralization, but fluoride alone has limited effects against plaque-biofilms. The rapid advancement of nanotechnology offers new approaches that could be used to both control plaque-biofilms and prevent dental caries.

Catalytic iron oxide nanoparticles (CAT-NP) have been shown to exhibit intrinsic enzyme mimetic activity similar to natural peroxidases, which can activate $\mathrm{H}_{2} \mathrm{O}_{2}$ in vitro [16] and thereby have been termed nanozymes [17-20]. In this prior work, the catalytic activity was observed to arise from the nanoparticles themselves rather than released $\mathrm{Fe}^{2+} / \mathrm{Fe}^{3+}$ via the Fenton reaction [21-24]. Hydrogen peroxide $\left(\mathrm{H}_{2} \mathrm{O}_{2}\right)$ is commonly used for general cleaning and disinfection purposes (at concentrations as high as 10\%) because it generates free radicals that exhibit antibacterial activity and could degrade polysaccharides [25-27]. However, $\mathrm{H}_{2} \mathrm{O}_{2}$ by itself has modest anti-plaque or caries-preventive effects [26, 27]. Iron oxide nanoparticles have been widely used clinically as contrast agents for magnetic resonance imaging because of their high biocompatibility and ability to penetrate biological matrices such as those present in tumors and atherosclerotic plaques [28-30]. However, their potential role as nanocatalysts for therapeutic application in vivo remains unexplored. Here, we demonstrate the multi-functional and $\mathrm{pH}$ responsive properties of CAT-NP capable of disrupting both plaque-biofilm formation and dental 
caries development mediated by $S$. mutans. CAT-NP perform peroxidase-like activity at acidic $\mathrm{pH}$ values that rapidly catalyzes hydrogen peroxide $\left(\mathrm{H}_{2} \mathrm{O}_{2}\right)$ in situ to simultaneously degrade the protective biofilm EPS-matrix and kill embedded bacteria with exceptional efficacy (>5-log reduction of cell viability). Unexpectedly, CAT-NP itself exhibits an additional pH-dependent property that reduces apatite demineralization under acidic $\mathrm{pH}$ conditions in vitro. Furthermore, topical application of CAT-NP in combination with $\mathrm{H}_{2} \mathrm{O}_{2}$ effectively suppresses the onset and severity of dental caries without causing deleterious effects on oral mucosal tissues in vivo.

\section{Materials and methods}

\subsection{Materials}

Chemicals and materials were supplied by Sigma-Aldrich unless otherwise specified. Hydroxyapatite discs (surface area, $2.7 \pm 0.2 \mathrm{~cm}^{2}$ ) were purchased from Clarkson Chromatography Products Inc. Amplex® UltraRed reagent was purchased from Thermo-Fisher Scientific.

\subsection{Iron oxide nanoparticle synthesis and characterization}

Catalytic iron oxide nanoparticles (CAT-NP) were synthesized in a solvothermal system and characterized as previously described [16]. Briefly, $0.82 \mathrm{~g}$ of $\mathrm{FeCl}_{3}$ was dissolved in $40 \mathrm{ml}$ of ethylene glycol to form a clear solution. Then, $3.6 \mathrm{~g}$ of sodium acetate was added to the solution with vigorous stirring for $30 \mathrm{~min}$. The mixture was then transferred to a $50 \mathrm{ml}$ Teflon-lined stainless-steel autoclave and incubated at $200{ }^{\circ} \mathrm{C}$ for $12 \mathrm{~h}$. After the autoclave cooled down to room temperature, the precipitate was collected, rinsed several times with ethanol and then dried at $60^{\circ} \mathrm{C}$ for $3 \mathrm{~h}$. The synthesized nanoparticles were characterized using scanning electron 
microscopy (SEM, JEOL 7500F, JEOL USA, Inc., Peabody, MA, USA) and transmission electron microscopy (TEM, JEOL 2010F) at the Singh Center for Nanotechnology, University of Pennsylvania. The peroxidase-like activity was tested via an established colorimetric method using 3,3',5,5'-tetramethylbenzidine (TMB) as substrate which generates a blue color with specific absorption at $652 \mathrm{~nm}$ after reacting with free-radicals catalyzed by CAT-NP in the presence of hydrogen peroxide over time [16]. Briefly, the reaction mixture of $500 \mu$ sodium acetate (NaOAc) buffer $(0.1 \mathrm{M}, \mathrm{pH} 4.5)$ containing $20 \mu \mathrm{g}$ CAT-NP, $1 \% \mathrm{H}_{2} \mathrm{O}_{2}$ and $100 \mu \mathrm{g}$ of TMB was incubated at room temperature and the blue color produced was measured at $652 \mathrm{~nm}$ [20]. Because the catalytic activity of CAT-NP is pH-dependent, we also examined the nanoparticle activity in NaOAc buffer at $\mathrm{pH} 5.5$ and 6.5. Two additional substrates, 3,3-diaminobenzidine (DAB) and Amplex® UltraRed (568/581 nm), were used with same reaction conditions to confirm the activity of CAT-NP. In a separate experiment, we also tested the catalytic activity of CAT-NP and the leached iron ions at acidic pH. Sodium acetate buffer (0.1M, pH 4.5) containing $500 \mu \mathrm{g}$ CAT-NP were incubated at room temperature for 0, 5, 30, 60 and $120 \mathrm{~min}$. The mixture was centrifuged, and the nanoparticle pellet and the supernatant were collected. The nanoparticles (resuspended in $0.1 \mathrm{M} \mathrm{NaOAc}$ buffer, $\mathrm{pH} 4.5$ ) or supernatant was incubated with $1 \% \mathrm{H}_{2} \mathrm{O}_{2}$ and $100 \mu \mathrm{g}$ TMB and the colorimetric reaction assessed as described above.

\subsection{Oral biofilm model}

Biofilms were formed using the saliva-coated hydroxyapatite disc model as described elsewhere, $[7,31,32]$ and shown in Supplementary Fig. 1. Streptococcus mutans UA159 cells, a proven virulent and well-characterized cariogenic pathogen, were grown in ultra-filtered (10-kDa cutoff; Millipore, Billerica, MA) tryptone-yeast extract (UFYTE) broth at $37^{\circ} \mathrm{C}$ and $5 \% \mathrm{CO}_{2}$ to mid- 
exponential phase. Briefly, the hydroxyapatite (HA) discs were vertically suspended in 24-well plates using a custom-made wire disc holder [7], and coated with filter-sterilized saliva for $1 \mathrm{~h}$ at $37^{\circ} \mathrm{C}[7,31,32]$; whole saliva was collected on ice, and it was clarified by centrifugation $(8,500$ $\left.\mathrm{g}, 4^{\circ} \mathrm{C}, 10 \mathrm{~min}\right)$ followed by filter-sterilization $(0.22 \mu \mathrm{m}$; ultra-low binding protein filter; Millipore, Billerica, MA) as described previously [7, 32]. Then, saliva-coated HA (sHA) discs were placed in $2.8 \mathrm{ml}$ of UFYTE culture medium with $1 \%(\mathrm{w} / \mathrm{v})$ sucrose $(\mathrm{pH} 7.0)$ containing $10^{5}$ colony forming units (CFU) of actively growing S. mutans cells per ml, and incubated at $37^{\circ} \mathrm{C}$ and $5 \% \mathrm{CO}_{2}$ for $19 \mathrm{~h}$. The culture medium was then replaced with fresh medium at $19 \mathrm{~h}$ and at $29 \mathrm{~h}$ until the end of the experimental period (43 h). The biofilms were collected and analyzed by (i) means of fluorescence imaging using multi-photon confocal microscopy and computational analysis (COMSTAT and Image J), (ii) microbiological assessment via standard culturing for determination of $\mathrm{CFU}$ and (iii) biochemical analysis for polysaccharides quantification using colorimetric methods as detailed previously [7, 31-34].

\subsection{Assessment of CAT-NP binding and activity within biofilm}

Quantitative assessment of CAT-NP binding onto biofilm was performed with inductively coupled plasma optical emission spectrometry (ICP-OES). Biofilms were topically exposed to $2.8 \mathrm{ml}$ of CAT-NP $\left(0,0.125,0.25,0.5,1\right.$ or $\left.2 \mathrm{mg} \mathrm{ml}^{-1}\right)$ in $0.1 \mathrm{M} \mathrm{NaOAc}(\mathrm{pH} 4.5)$ for 5 or $10 \mathrm{~min}$ at room temperature at specific time-points as described in Supplementary Fig. 1. The treated biofilms were dip-washed three times in sterile saline solution $(0.89 \% \mathrm{NaCl})$ to remove excess and unbound agents, and then transferred to the culture medium. At the end of the experimental period (43h), the biofilm was removed from sHA discs and homogenized via water bath sonication followed by probe sonication (30 s pulse at an output of 7W; Branson Sonifier 150, 
Branson Ultrasonics, Danbury, CT) as described previously [7, 35]; the sonication procedure does not kill bacterial cells, while providing optimum dispersal and maximum recoverable counts. The homogenized suspension was centrifuged, and the biofilm pellet washed twice with water to remove unbound material. The pellet was then dissolved with $250 \mu \mathrm{l}$ aqua regia $\left(\mathrm{HC} 1 / \mathrm{HNO}_{3}=3: 1\right)$ at $60^{\circ} \mathrm{C}$ overnight $[28,36]$. Then, $4.75 \mathrm{ml}$ Milli-Q water was added, and the sample analyzed by ICP-OES for iron content. Intact biofilms were also examined with environmental SEM (FEI 600 Quanta, FEI, Hillsboro, OR, USA) and iron analyzed via energy dispersive spectroscopy (EDS) on the same SEM. In a separate experiment, the catalytic activity of CAT-NP within intact biofilms was also assessed. Briefly, CAT-NP or vehicle-control (buffer) treated biofilms (at $43 \mathrm{~h}$ ) were dip-washed with $0.1 \mathrm{M} \mathrm{NaAc}$ buffer (pH 4.5) three times and transferred to the reaction buffer (0.1 M NaOAc buffer ( $\mathrm{pH} 4.5)$ containing TMB and $\mathrm{H}_{2} \mathrm{O}_{2}$ only. After 10 minutes, the biofilms were removed and the colorimetric reaction assessed as described in section 2.2. In another experiment, we also assessed the catalytic activity of the insoluble and soluble fraction of the biofilm. Briefly, the homogenized biofilm was centrifuged, and the insoluble pellet and the supernatant were collected. The pellet was washed once with 0.5 $\mathrm{ml}$ of $\mathrm{NaOAc}$ buffer ( $\mathrm{pH} 4.5$ ), centrifuged and the supernatant combined. The pellet was resuspended in the same volume of the combined supernatant. Then, the pellet suspension and the supernatant (soluble fraction) were analyzed for iron amounts via ICP-OES and catalytic activity using colorimetric reaction with $\mathrm{TMB}$ and $\mathrm{H}_{2} \mathrm{O}_{2}$. For $\mathrm{pH}$-dependent catalytic assay, the CAT-NP treated biofilms were dip-washed with $0.1 \mathrm{M} \mathrm{NaAc}$ buffer at various $\mathrm{pH}$ values $(\mathrm{pH}$ 4.5, $\mathrm{pH} 5.5$ or $\mathrm{pH}$ 6.5) three-times, and then incubated in each of the corresponding $\mathrm{pH}$ buffer for 10 minutes. Then, the biofilm was transferred to the reaction buffer with each corresponding $\mathrm{pH}$ ( $\mathrm{pH} 4.5$, $\mathrm{pH} 5.5$ or $\mathrm{pH} 6.5$ ) containing $\mathrm{TMB}$ and $\mathrm{H}_{2} \mathrm{O}_{2}$ for colorimetric assay. 


\subsection{Spatial distribution of CAT-NP within intact biofilm architecture}

We examined the spatial distribution of CAT-NP, bacterial cells and the EPS-matrix within intact biofilms (43 h) using methods optimized for biofilm imaging and quantification via multiphoton confocal microscopy and computational analysis [7, 31, 32]. Briefly, $1 \mu \mathrm{M}$ AlexaFluor 647-dextran conjugate (647/668 nm; Molecular Probes) was added to the culture medium during the formation of $S$. mutans biofilm. The fluorescently-labelled dextran is directly incorporated during EPS matrix synthesis over the course of biofilm development, but does not stain the bacterial cells $[7,31,32]$. The bacterial cells in the biofilm were stained with $2.5 \mu \mathrm{M}$ SYTO 9 green-fluorescent nucleic acid stain (485/498 nm; Molecular Probes). The CAT-NP was detected via their inherent non-linear optical property using multiphoton confocal microscopy [37]. The imaging was performed using multi-photon Leica SP5 microscope with 20×LPlan (numerical aperture, 1.05) water immersion objective. The excitation wavelength was $780 \mathrm{~nm}$, and the emission wavelength filter for SYTO 9 was a 495/540 OlyMPFC1 filter, while the filter for Alexa Fluor 647 was an HQ655/40M-2P filter. The excitation wavelength for CAT-NP was 910 nm which did not excite SYTO 9 or Alexa Fluor 647. The confocal images were analyzed using software for simultaneous visualization and quantification of EPS, bacterial cells and CAT-NP within intact biofilms. Amira 5.0.2 (Mercury Computer Systems Inc., Chelmsford, MS) was used to create 3D renderings of each component (EPS, bacteria and CAT-NP) of the biofilms for visualization of the 3D architecture while COMSTAT and ImageJ were used for quantitative analysis as described previously [7, 31]. 


\subsection{Biofilm disruption and glucan degradation with CAT-NP activated $\mathrm{H}_{2} \mathrm{O}_{2}$}

To assess the anti-biofilm efficacy of CAT-NP bound within biofilms, the sHA discs and biofilms were topically treated twice-daily by placing them in $2.8 \mathrm{ml}$ of CAT-NP $\left(0.5 \mathrm{mg} \mathrm{ml}^{-1}\right)$ in $0.1 \mathrm{M} \mathrm{NaOAc}(\mathrm{pH} 4.5)$ or vehicle-control (buffer only) for 5 or $10 \mathrm{~min}$ as described in Supplementary Fig. 1. After each treatment, the biofilms were washed 3 times with sterile saline to remove unbound material, and transferred to the culture medium. At the end of the experimental period $(43 \mathrm{~h})$, the CAT-NP and vehicle treated biofilms were placed in $2.8 \mathrm{ml}$ of $\mathrm{H}_{2} \mathrm{O}_{2}(0.1$ to $1 \%)$ or water. After hydrogen peroxide exposure, the biofilms were removed and homogenized as described in section 2.4, and subjected to microbiological and biochemical analysis as detailed previously [7, 31-35]. The total number of viable cells in each of the treated biofilms was determined by CFU, while the water soluble and water insoluble EPS were extracted and quantified via colorimetric assays [7, 31-35]. We also examined the dynamics of biofilm disruption after topical treatments with CAT-NP followed by $\mathrm{H}_{2} \mathrm{O}_{2}$ exposure at $19 \mathrm{~h}, 29$ $\mathrm{h}$ and $43 \mathrm{~h}$. The biofilm 3D architecture, the EPS and bacterial cell accumulation were analyzed via confocal microscopy and computational analysis as described in section 2.5. For assessment of EPS degradation in vitro, $100 \mu \mathrm{g}$ of (insoluble or soluble) glucans produced by purified glucosyltransferases B or C (GtfB or GtfD [42]) were mixed with each of the treatment solutions (in $0.1 \mathrm{M} \mathrm{NaOAc}, \mathrm{pH} 4.5$ ) and incubated at $37{ }^{\circ} \mathrm{C}$ for $30 \mathrm{~min}$. After reaction, the amount of reducing sugars was determined by the Somogyi-Nelson colorimetric assay [31, 33].

\subsection{Saliva-coated HA beads acid-dissolution and iron release assays}

In this acid-dissolution assay, $10 \mathrm{mg}$ of sHA beads were incubated in $1 \mathrm{ml}$ of $0.1 \mathrm{M} \mathrm{NaOAc}$ buffer ( $\mathrm{pH} 4.5$ ) containing $0.5 \mathrm{mg} \mathrm{ml}^{-1} \mathrm{CAT}-\mathrm{NP}$ for $2 \mathrm{~h}$ with rocking at room temperature. Then, 
the supernatant was removed and sHA beads were resuspended again in fresh $1 \mathrm{ml}$ of acidic NaOAc buffer and incubated as described above. The same procedure was conducted with sHA beads without CAT-NP (control) as well as with sHA beads (with or without CAT-NP) in $0.1 \mathrm{M}$ $\mathrm{NaOAc}$ buffer at pH 7.0. An aliquot of sHA immediately before and after acid-dissolution was taken and analyzed via optical microscopy (OM) and SEM. In parallel, the remaining sHA beads were oven-dried and weighed for determination of dry-weight. The remaining dry-weight of sHA treated with CAT-NP was compared to control group to evaluate the efficiency of reduction of demineralization. For iron release assay, $0.5 \mathrm{mg} \mathrm{ml}^{-1} \mathrm{CAT}-\mathrm{NP}$ was incubated in $0.1 \mathrm{M} \mathrm{NaOAc}$ $(\mathrm{pH} 4.5)$ at room temperature for $0,3,5,10,30,60,120 \mathrm{~min}$, respectively. The mixture was centrifuged and the supernatant was collected for iron concentration measurement using Iron Assay Kit (Sigma-Aldrich) or ICP-OES. The iron release in 0.1 M NaOAc (pH 7) was conducted as control following the same procedure described above.

\subsection{Biocompatibility assessments}

The in vitro biocompatibility of CAT-NP was investigated in BJ5ta and primary oral epithelial cells using the MTS [(3-(4,5-dimethylthiazol-2-yl)-5-(3-carboxymethoxyphenyl)-2-(4sulfophenyl)-2H-tetrazolium)] assay (CellTiter 96 cell proliferation assay kit; Promega, WI, USA). Human fibroblast (BJ5ta) cells were purchased from ATCC (Manassas, VA, USA). Primary human gingival epithelial cells (HGECs) were kindly provided by Dr. Manju Benakanakere (School of Dental Medicine, University of Pennsylvania). The cell viability assay was performed in 96 well flat bottom microplates (Corning, NY, USA) according to a previously published protocol [38]. In brief, 10,000 cells were seeded in each well and then the plate was incubated in a $\mathrm{CO}_{2}$ incubator until confluence for 24 hours. Then, the cell monolayer was 
washed once with sterile phosphate buffered saline (PBS). $100 \mu$ l of different concentrations of CAT-NP (i.e. 10, 50, 100 and $500 \mu \mathrm{g} \mathrm{ml}^{-1}$ ) prepared in cell culture media were added to 6 wells per concentration. Then the plate was incubated in a $\mathrm{CO}_{2}$ incubator for 5 minutes to mimic the exposures to biofilms as described above. The cell culture media was then removed from each well, the cell monolayer was washed twice with PBS, and $100 \mu 1$ of complete cell culture media was added to each well. After 24 hours of incubation the cell culture media was removed and the cell monolayer was washed with PBS. $20 \mu 1$ of MTS reagent and $100 \mu 1$ of complete cell culture media were added to each well and the plate was placed in a $\mathrm{CO} 2$ incubator for 1 hour. At that point, the absorbance at $490 \mathrm{~nm}$ was recorded using a micro-plate reader. The relative cell viability was calculated compared to control.

\subsection{In vivo efficacy of $\mathrm{CAT}-\mathrm{NP} / \mathrm{H}_{2} \mathrm{O}_{2}$}

Animal experiments were performed on a well-established rodent model of dental caries disease as described previously [35, 39, 40]. Briefly, Sprague-Dawley rats, 15 days old, were purchased with their dams from Harlan Laboratories (Madison, WI, USA). Then, the animals were infected orally using an actively growing (mid-logarithmic) culture of $S$. mutans UA159, and their infection was checked via oral swabbing. To simulate a clinical situation, we developed a combination therapy consisting of 1-minute topical treatment of CAT-NP (at $0.5 \mathrm{mg} \mathrm{ml}^{-1}$ ) immediately followed by $\mathrm{H}_{2} \mathrm{O}_{2}$ (at $1 \%$, w/v) exposure (CAT-NP/ $\mathrm{H}_{2} \mathrm{O}_{2}$ ). Thus, the infected animals were randomly placed into treatment groups (12 animals/group), and their teeth were treated topically twice daily using a custom-made applicator. The treatment groups included: (1) control (0.1 M NaOAc buffer, $\mathrm{pH} 4.5)$, (2) CAT-NP only $\left(0.5 \mathrm{mg} \mathrm{ml}^{-1}\right)$, (3) $1 \% \mathrm{H}_{2} \mathrm{O}_{2}$ only, and (4) CAT-NP+ $\mathrm{H}_{2} \mathrm{O}_{2}\left(0.5 \mathrm{mg} \mathrm{ml}^{-1}\right.$ CAT-NP with $\left.1 \% \mathrm{H}_{2} \mathrm{O}_{2}\right)$. Each group was provided the National 
Institutes of Health cariogenic diet 2000 and 5\% sucrose water ad libitum. The experiment proceeded for 3 weeks (21 days); all animals were weighed weekly, and their physical appearance was noted daily. All animals gained weight equally among the experimental groups and remained in good health during the experimental period. At the end of the experimental period, the animals were sacrificed, and the jaws were surgically removed and aseptically dissected; the left jaws were sonicated in sterile saline solution and S. mutans infection in all groups were confirmed as determined using culturing (selective mitis salivarius with bacitracin medium) and qPCR (quantitative polymerase chain reaction) methods (S. mutans specific probe) as described previously [31-35]. All of the jaws were defleshed, and the teeth were prepared for caries scoring according to Larson's modification of Keyes' system [32, 35, 39]. Determination of caries score of the codified jaws was performed by a calibrated examiner. Furthermore, both the gingival and palatal tissues were collected and processed for hematoxylin and eosin (HE) staining for histopathological analysis by an oral pathologist (Dr. Faizan Alawi, Penn Oral Pathology). This study was reviewed and approved by the University of Pennsylvania Institutional Animal Care and Use Committee (IACUC \#805529).

\subsection{Statistical Analysis}

Statistical analyses for the experimental data were performed in SAS 9.5 (SAS Institute) as described previously [32]. For the in vitro studies, treatments were compared using regression models to obtain overall tests of equality and pairwise comparisons. The significance was set at $5 \%$, and no adjustments were made for multiple comparisons. For the animal study, an analysis of outcome measures was done with transformed values of the measures in order to stabilize 
variances [32]. The data were then subjected to analysis of variance (ANOVA) in the TukeyKramer test for all pairs. The level of significance was set at $5 \%$.

\section{Results}

\subsection{CAT-NP are retained within biofilm structure following topical treatments}

Effective retention of nanoparticles within plaque-biofilm and in situ activity are required for biological efficacy in vivo $[8,9,35]$. Thus, we first examined whether CAT-NP are retained within biofilms following topical treatments with short-term exposures (5 or $10 \mathrm{~min}$ ) (Supplementary Fig. 1). We synthesized CAT-NP $213 \pm 26 \mathrm{~nm}$ in diameter with intrinsic peroxidase-like activity (Supplementary Fig. 2). Biofilms were formed on saliva-coated hydroxyapatite (sHA) surfaces (tooth enamel-like material) using S. mutans, a well-established biofilm-forming, acidogenic and matrix-producing oral pathogen [4] (Supplementary Fig. 1). To mimic a pathogenic situation, biofilms were formed in the presence of sucrose, which provides a substrate for EPS synthesis and acid production [4]; $\mathrm{pH}$ values reaches 4.5-5.0 in our biofilm model (by measuring the $\mathrm{pH}$ of the culture medium as well as via Beetrode $\mathrm{pH}$ electrode [40] or fluorescence $\mathrm{pH}$ analysis [7]), consistent with plaque $\mathrm{pH}$ at diseased sites in humans [41, 42]). We observed that CAT-NP bind to biofilms as demonstrated by scanning electron microscopy (Fig. 1b) and energy dispersive spectroscopy (Fig. 1b2), and quantified via inductively coupled plasma optical emission spectrometry (Fig. 1c). The binding of CAT-NP to biofilms reached a plateau at $0.5 \mathrm{mg} \mathrm{ml}^{-1}$ (Fig. 1c) since higher concentrations did not lead to significant increases in the amount of iron in the biofilms. To determine retention and the spatial distribution of CATNP within intact biofilm 3D architecture, we used multiphoton confocal microscopy and computational analysis [7, 31]. The EPS and bacterial cells were labelled with an Alexa Fluor 
647 (in red) and SYTO 9 (in green), while CAT-NP (in white) were detected via their inherent non-linear optical property [37] (Fig. 1d-i). The in situ imaging revealed that nanoparticles were effectively retained throughout the biofilm structure following topical treatments (Fig. 1e-i). Quantitative analysis across the biofilm thickness (from top to bottom) showed that most of the nanoparticles were found between 25 and $150 \mu \mathrm{m}$ depth (Fig. 1j), where both EPS and bacterial biomass are most abundant (Fig. 1k).

\subsection{CAT-NP efficiently catalyze $\mathrm{H}_{2} \mathrm{O}_{2}$ in situ}

We then investigated whether CAT-NP attached to biofilms were capable of catalyzing the breakdown of $\mathrm{H}_{2} \mathrm{O}_{2}$ at acidic $\mathrm{pH}(\mathrm{pH}$ 4.5) to produce free radicals in situ, as determined by a colorimetric method using 3,3',5,5'-tetramethylbenzidine (TMB) [16]. The nanoparticles bound to biofilms catalyzed the reaction of TMB (which serves as a peroxidase substrate) in the presence of $\mathrm{H}_{2} \mathrm{O}_{2}$ to produce a blue color (Fig. 2a), with maximum absorbance at $652 \mathrm{~nm}$, as a result of free radical generation. The experiment was repeated using an additional peroxidase substrate (di-azo-aminobenzene) to further confirm peroxidase-like activity in CAT-NP treated biofilms (Supplementary Fig. 3). Consistent with the amount of CAT-NP adsorbed within the biofilm, the highest catalytic activity was achieved at concentrations between 0.5 to $2.0 \mathrm{mg} \mathrm{ml}^{-1}$, under the conditions tested (Fig. 2a). Increases in activity were relatively small for concentrations higher than $0.5 \mathrm{mg} \mathrm{ml}^{-1}$, therefore we selected this dose for further experiments since $0.5 \mathrm{mg} \mathrm{ml}^{-1}$ exhibited high catalytic activity with a relatively low amount of the nanoparticle. Because $\mathrm{H}_{2} \mathrm{O}_{2}$ catalysis by CAT-NP depends on $\mathrm{pH}$ [16] (Supplementary Fig. 4), we measured the peroxidase-like activity of the biofilm-bound nanoparticle when incubated in buffer with $\mathrm{pH}$ values varying from 4.5 to 6.5 . After incubating the biofilms in each of the 
buffers, the catalytic activity was determined using TMB in the presence of $\mathrm{H}_{2} \mathrm{O}_{2}$ in the buffer at the specific $\mathrm{pH}$ values. We found that CAT-NP attached to biofilms exert greater catalytic efficiency at acidic $\mathrm{pH}(4.5-5.5)$ (Fig. 2b).

Previous work demonstrated that the activation of hydrogen peroxide by iron oxide nanoparticles is due to activity from the iron oxide nanoparticles themselves as opposed to the $\mathrm{H}_{2} \mathrm{O}_{2}$ breakdown caused by $\mathrm{Fe}^{2+} / \mathrm{Fe}^{3+}$ Fenton reaction [16]. Others have also shown that the catalytic activity is derived from iron oxide nanoparticles rather than released iron ions [17, 2124]. However, since our experiments focus on a novel setting with low $\mathrm{pH}$ (i.e. cariogenic biofilms), we studied the contribution of free iron ions to the observed catalytic activity. First, we observed trace amounts of free iron leached from either CAT-NP in acidic $\mathrm{pH}$ buffer $(\mathrm{pH}$ 4.5) (Supplementary Fig. 5) or in the soluble-fraction of the CAT-NP-treated biofilm (Supplementary Fig. 6). Furthermore, the catalytic activity of the solution-phase and soluble-fraction was minimal (Supplementary Fig. 5 and 6). Altogether, the data show that CAT-NP are retained within biofilms following brief topical applications, and display pH-dependent catalysis of $\mathrm{H}_{2} \mathrm{O}_{2}$ in situ.

\subsection{CAT-NP activates $\mathrm{H}_{2} \mathrm{O}_{2}$ for rapid bacterial killing and EPS degradation amplifying anti- biofilm efficacy}

We next examined whether CAT-NP mediated $\mathrm{H}_{2} \mathrm{O}_{2}$ catalysis and generation of free-radicals in situ can kill embedded bacteria and degrade the EPS-matrix within biofilms. Biofilms treated with CAT-NP $\left(0.5 \mathrm{mg} \mathrm{ml}^{-1}\right)$ were immediately exposed to low concentrations of $\mathrm{H}_{2} \mathrm{O}_{2}(0.1$ to $1 \%, \mathrm{v} / \mathrm{v}$ ), and the number of viable cells and EPS content determined (Fig. 3a,b and Supplementary Fig. 7). We observed an exceptionally strong biocidal effect against S. mutans 
within biofilms, with $>99.9 \%$ killing in 5 minutes; exposure of CAT-NP treated biofilms with $1 \% \mathrm{H}_{2} \mathrm{O}_{2}$ caused $>5$-log reduction of viable cells compared to control biofilms or CAT-NP treated biofilms without $\mathrm{H}_{2} \mathrm{O}_{2}$ (Fig. 3a). The combination of CAT-NP and $\mathrm{H}_{2} \mathrm{O}_{2}$ was $>5,000$-fold more effective in killing $S$. mutans biofilm cells than $\mathrm{H}_{2} \mathrm{O}_{2}$ alone (Fig. 3a), suggesting a synergistic effect between CAT-NP and $\mathrm{H}_{2} \mathrm{O}_{2}$ to potentiate the killing efficacy of the agents. We also found that the $\mathrm{H}_{2} \mathrm{O}_{2}$ activation by CAT-NP is several-fold more effective in killing biofilm cells than chlorhexidine at $0.12 \%(\mathrm{v} / \mathrm{v}$; typical concentration used clinically $[10,11])$ (Supplementary Fig. 8).

Given that free-radicals produced from $\mathrm{H}_{2} \mathrm{O}_{2}$ catalysis can also degrade polysaccharides in vitro [43], we hypothesized that the amount of EPS in the CAT-NP treated biofilms would be reduced in situ following exposure to $\mathrm{H}_{2} \mathrm{O}_{2}$. Biochemical analysis revealed that the amounts of insoluble and, to a lesser extent, soluble EPS were significantly reduced compared to control and to either $\mathrm{H}_{2} \mathrm{O}_{2}$ or CAT-NP alone (Fig. 3b). The insoluble EPS are comprised primarily of $\alpha 1,3-$ linked glucans while soluble EPS are mostly a1,6-linked glucans, which are produced by $S$. mutans-derived glucosyltransferases (Gtfs) [44]. Therefore, we further examined whether purified extracellular glucans produced by GtfB (which synthesizes $\alpha 1,3$-linked glucans) and GtfD ( $\alpha 1,6$-linked glucans) are degraded following incubation with CAT-NP in the presence or absence of $\mathrm{H}_{2} \mathrm{O}_{2}$. Fig. 3c shows that both glucans (particularly from $\mathrm{GtfB}$ ) were broken down as determined by measuring the amount of glucose released from the polysaccharide following CAT-NP/ $\mathrm{H}_{2} \mathrm{O}_{2}$ treatment. In contrast, $\mathrm{H}_{2} \mathrm{O}_{2}$ alone or CAT-NP alone failed to cleave either glucan, an observation consistent with their inability to reduce EPS within biofilms. Collectively, the in vitro data suggest that the combination of CAT-NP with $\mathrm{H}_{2} \mathrm{O}_{2}$ could severely suppress biofilm development by $S$. mutans. 


\subsection{Dynamics of biofilm disruption after topical treatments with $\mathrm{CAT}-\mathrm{NP} / \mathrm{H}_{2} \mathrm{O}_{2}$}

Since we have shown that CAT-NP are retained within biofilms and catalyze $\mathrm{H}_{2} \mathrm{O}_{2}$ in situ for enhanced biofilm disruption, we developed a clinically feasible combination therapy consisting of topical treatment of CAT-NP (at $0.5 \mathrm{mg} \mathrm{ml}^{-1}$ ) immediately followed by $\mathrm{H}_{2} \mathrm{O}_{2}$ (at $1 \%$, v/v) exposure (CAT-NP/ $\mathrm{H}_{2} \mathrm{O}_{2}$ ), twice daily. The treatment regimen was initially tested in vitro to assess whether biofilms could be disrupted by CAT-NP in combination with $\mathrm{H}_{2} \mathrm{O}_{2}$. Confocal microscopy imaging revealed that treatments with CAT-NP/ $\mathrm{H}_{2} \mathrm{O}_{2}$ impaired both the accumulation of bacterial cells (in green) and the development of EPS-matrix (in red) (Fig. 4a,b; Supplementary Fig. 9). While 5 minutes CAT-NP treatments followed by $\mathrm{H}_{2} \mathrm{O}_{2}$ exposure twicedaily achieved near complete inhibition of biofilm formation by S. mutans, even as little as 1minute exposure caused significant disruption of biofilm accumulation (Supplementary Fig.10). In contrast, topical treatments with CAT-NP or $\mathrm{H}_{2} \mathrm{O}_{2}$ alone had limited anti-biofilm effects in vitro, consistent with synergistic potentiation when these agents are used in combination.

\subsection{Biocompatibility of CAT-NP in vitro}

We also assessed the effect of CAT-NP on the cell viability of oral epithelial cells and fibroblasts. We tested a range of concentrations $(10-500 \mu \mathrm{g} / \mathrm{ml})$ using a similar protocol to that used against the biofilms, i.e. a 5 min exposure time, followed by 24 hours of incubation with fresh cell culture media (Supplemental Fig. 11). The viability of these cells was unaffected by any of the concentrations tested, suggesting the biocompatibility of these nanoparticles, as observed in previous studies [28, 29, 36]. 


\subsection{The combination of CAT-NP and $\mathrm{H}_{2} \mathrm{O}_{2}$ effectively suppresses dental caries in vivo}

In the human mouth, therapeutic agents are applied topically, which poses a challenge because such agents should avoid rapid clearance and be retained for sufficient duration to exert their effects. Given the exceptional topical anti-biofilm effects we observed in vitro, we tested whether CAT-NP/ $\mathrm{H}_{2} \mathrm{O}_{2}$ could suppress the onset and severity of dental caries in vivo using a rodent model of the disease [35, 39, 40]. We applied our agents topically (orally-delivered; 100 $\mu \mathrm{L}$ per rat) twice-daily for 3 weeks, with a short exposure (1-minute) time to be amenable with the animal model and to simulate more closely the clinical use by humans. In this model, teeth progressively develop carious lesions (analogous to those observed in humans), proceeding from initial areas of enamel demineralization (Fig. 5a, green arrow) to further destruction (blue arrows), leading to the most severe lesions characterized by cavitation (red arrow).

CAT-NP/ $\mathrm{H}_{2} \mathrm{O}_{2}$ treatments were highly effective in disrupting caries development. Quantitative caries scoring analyses revealed that CAT-NP/ $\mathrm{H}_{2} \mathrm{O}_{2}$ significantly attenuated both the initiation (Fig $5 b$ ) and severity (Fig $5 \mathrm{c}$ ) of the lesions (vs. vehicle control; $P \leq 0.001$ ), and completely blocked extensive enamel damage, preventing the onset of cavitation. In sharp contrast, treatments with $\mathrm{H}_{2} \mathrm{O}_{2}$ alone were without significant effect, while CAT-NP showed some reduction of the severity of carious lesions (vs. vehicle-control; Fig. 5b,c). Importantly, we observed no deleterious effects on rats that received topical applications of CAT-NP/ $\mathrm{H}_{2} \mathrm{O}_{2}$. All animals treated with CAT-NP/ $\mathrm{H}_{2} \mathrm{O}_{2}$ gained body weight similarly to those treated with vehiclecontrol (buffer). Furthermore, histopathological analysis of gingival and palatal tissues from CAT-NP/ $\mathrm{H}_{2} \mathrm{O}_{2}$-treated animals showed no sign of harmful effects, such as proliferative changes, inflammatory responses, and/or necrosis, when compared to vehicle-treated animals (Supplementary Fig. 12). 
Surprisingly, we found that CAT-NP alone could reduce the severity of caries lesions to some extent in the above animal experiment. Iron ions appear to inhibit dental caries, possibly by interfering with the enamel demineralization process in addition to antibacterial effects [45, 46]. We observed that trace amounts of iron ions can be released from CAT-NP when incubated at acidic $\mathrm{pH}$ (4.5), but not at $\mathrm{pH} 7.0$ (Fig. 6a). Therefore, we investigated whether CAT-NP could reduce apatitic dissolution at acidic $\mathrm{pH}$. Saliva-coated hydroxyapatite (sHA) beads were incubated in acidic sodium acetate buffer ( $\mathrm{pH} 4.5)$ with or without CAT-NP, and then examined by measurement of the amount of remaining sHA as well as via SEM after acid incubation (Fig. 6b,c). sHA beads without CAT-NP were almost completely dissolved. In contrast, aciddissolution of sHA was significantly reduced in the presence of CAT-NP. As expected, sHA beads incubated in sodium acetate buffer at $\mathrm{pH} 7.0$ (with or without CAT-NP) were devoid of any demineralization (data not shown). These findings suggest CAT-NP may perform an additional $\mathrm{pH}$-dependent mechanism to help prevent the development of dental caries by directly reducing apatite demineralization under acidic conditions.

\section{Discussion}

Despite the high prevalence of dental caries worldwide, current antimicrobial therapies (such as $\mathrm{CHX)} \mathrm{have} \mathrm{limited} \mathrm{anti-caries} \mathrm{efficacy} \mathrm{[8-15],} \mathrm{resulting} \mathrm{in} \mathrm{expenditures} \mathrm{of}>\$ 40$ billion annually in the US alone [6]. Dental caries is a pathological process characterized by the ability of biofilm matrix-embedded bacteria to firmly adhere and persist on a surface, modifying the local microenvironment [4-6, 44]. Cariogenic biofilms can create highly acidic milieu that erode the enamel apatite of teeth via acid-dissolution, eventually leading to cavitation [4-6, 41, 44]. 
New nanotechnologies have expanded the opportunities to control such harmful biofilms, which include antibacterial nanoparticles or coatings on dental materials $[8,9,12,47]$. Furthermore, nano-apatites are capable of enhancing remineralization of early carious lesions, although they are devoid of anti-biofilm actions [8]. In this study, we have developed a novel multi-functional approach with both anti-plaque and anti-caries properties using nanoparticles with catalytic properties (termed nanocatalysts). It integrates a biocompatible and $\mathrm{pH}$-responsive strategy that facilitates matrix disruption, enhances anti-bacterial action within plaque-biofilms, and at the same time reduces apatite dissolution under acidic conditions.

As summarized in Fig. 7, our approach has 5 major biological effects: (1) CAT-NP are retained within 3D biofilm structure after brief topical exposure; (2) CAT-NP rapidly catalyze low concentrations of $\mathrm{H}_{2} \mathrm{O}_{2}$ at acidic $\mathrm{pH}$ to produce free radicals in situ that simultaneously (3) degrade EPS and (4) kill bacteria embedded within biofilms. Furthermore, (5) we unexpectedly found a new property for CAT-NP that can reduce acid dissolution of hydroxyapatite. Thus, compared to other antimicrobial nanomaterials, such as silver nanoparticles, it provides an important additional mechanism for caries prevention. It is noteworthy that the treatment time is critical when assessing the efficacy of topical agents for clinical therapy, such as mouthwash, toothpastes or gels. In our experiments, as little as 1-minute exposure of CAT-NP/ $\mathrm{H}_{2} \mathrm{O}_{2}$ displayed potent therapeutic activity in a rodent caries model. To our knowledge, this work presents original evidence to exploit nanocatalysts for in vivo activation of an antimicrobial agent to create a potent plaque-biofilm disruptor and caries preventive therapy for topical use.

The effective retention and $\mathrm{pH}$-responsive properties of CAT-NP provide unique benefits to our approach such as localized deposition of the nanoparticles over time and in situ bioactivity when $\mathrm{pH}$ becomes acidic. Such properties have the potential for sustained $\mathrm{pH}$-activation of $\mathrm{H}_{2} \mathrm{O}_{2}$ 
at sites of S. mutans colonization and active sugar metabolism [4, 5, 44]. We demonstrated that CAT-NP with enhanced catalytic activity at acidic $\mathrm{pH}$ potentiated the killing efficacy of $\mathrm{H}_{2} \mathrm{O}_{2}$ against $S$. mutans within biofilms, while the free-radical generation was substantially attenuated at higher $\mathrm{pH}$ values (e.g. $\mathrm{pH}$ 6.5). Although leached free iron ions and $\mathrm{H}_{2} \mathrm{O}_{2}$ can produce free radicals via Fenton reaction, only trace amounts of free irons are available, which have a very small contribution to the overall catalytic activity, consistent with previous studies $[16,17,21$ 24]. In addition, previous studies have shown that repeated reaction of $\mathrm{H}_{2} \mathrm{O}_{2}$ on the nanoparticle surface does not affect its catalytic activity [48, 49], indicating that $\mathrm{H}_{2} \mathrm{O}_{2}$ exposure (especially in the context of short-term biofilm treatments) may not cause nanoparticle degradation. Thus, the intact CAT-NP played a major role as a nanocatalyst [17] to activate $\mathrm{H}_{2} \mathrm{O}_{2}$ catalysis to degrade biofilm matrix and kill bacteria in our experiments.

The reduction of insoluble EPS (primarily glucans) is highly relevant because glucans comprise up to $20 \%$ of dental plaque dry-weight, form the core of the extracellular matrix and have been associated with dental caries both in rodent models and in clinical studies [as reviewed in 44]. Our data suggest that glucans are degraded via oxidative cleavage through generation of radical oxidants from CAT-NP activation of $\mathrm{H}_{2} \mathrm{O}_{2}$. Interestingly, insoluble glucans (rich in $\alpha 1,3-$ linked glucose) appear to be degraded more effectively than soluble glucans (comprised primarily of $\alpha 1,6$-linked glucose). The reasons why $\alpha 1,3$ linkage is more susceptible to cleavage than $\alpha 1,6$-linkage and the exact mechanisms by which free radicals generated in situ break-down the EPS matrix remain unclear. Studies on EPS structure, such as linkage and compositional analyses, shall reveal the exact identity of the glycosidic bond cleavage sites and the degraded end products. Furthermore, the mechanisms of bacterial killing can be determined by examining oxidative stress, DNA damage and other processes in response to CAT-NP/ $\mathrm{H}_{2} \mathrm{O}_{2}$ in a dose- 
dependent manner. Future investigations on the effects of CAT-NP/ $\mathrm{H}_{2} \mathrm{O}_{2}$ on additional matrix components (e.g. fructans, eDNA and proteins) as well as against other bacteria (including spirochetes, lactobacilli and other cariogenic species) using mixed-species biofilm models akin to in vivo situation are certainly warranted.

Although the leached iron is a small fraction of the total, with minimal contribution to catalysis, the trace iron released by CAT-NP at acidic $\mathrm{pH}$ values can help reduce hydroxyapatite acid-dissolution. The effects may be related to the ability of iron ions to incorporate into the apatitic crystal by reacting with phosphate and creating a barrier of ferric phosphate that could prevent demineralization $[46,50,51]$. However, detailed studies using human tooth enamel combined with X-ray diffraction and microhardness/micro-Computed Tomography testing are needed to elucidate how CAT-NP affect enamel structure and/or disrupt apatite acid-dissolution.

Collectively, the data indicate that the combined anti-plaque effects of CAT-NP activation of $\mathrm{H}_{2} \mathrm{O}_{2}$ with inhibition of apatitic acid-dissolution help to thwart the onset and progression of dental caries in vivo. Although there are some limitations of the rodent model due to monoinfection with $S$. mutans, it is noteworthy that the rat harbors complex and mixed oral flora even after infection with S. mutans. In the rodent model of the disease, initial caries develops in 7-10 days and reaches moderate to severe lesions in 21 days. The combination therapy reduced both the initiation and the extent of carious lesions severity, preventing the onset of cavitation altogether. Although the disease process is not completely blocked, further enhancement of CAT-NP/ $\mathrm{H}_{2} \mathrm{O}_{2}$ efficacy as well as inclusion of fluoride in the system may lead to full prevention of dental caries. Ultimately, our therapeutic approach should reach maximum therapeutic effects with a 1-minute (or less) exposure time, and its efficacy evaluated in clinical studies. 


\section{Conclusion}

In summary, we have developed a novel therapeutic strategy based on catalytic nanoparticles with peroxidase-like activity and validated its in vivo efficacy with $\mathrm{H}_{2} \mathrm{O}_{2}$ for treatment of dental caries, a prevalent and costly biofilm-associated oral disease. The CAT-NP activation of $\mathrm{H}_{2} \mathrm{O}_{2}$ can effectively disrupt biofilm EPS matrix and simultaneously kill bacteria in acidic microenvironments in a short time for biofilm control and caries prevention. Intriguingly, CATNP by itself is also capable of reducing hydroxyapatite demineralization in vitro, which can contribute directly in attenuating the severity of carious lesions in vivo. Furthermore, free-radical generation is acid $\mathrm{pH}$ dependent, and CAT-NP/ $\mathrm{H}_{2} \mathrm{O}_{2}$ showed no deleterious effects on oral mucosal tissues in vivo following daily oral topical treatments. Our approach may have broader 
reach as EPS are major components of matrices in many biofilms $[1,2]$ and acidic $\mathrm{pH}$ microenvironments can be found in other pathological conditions [56, 57], such as in cystic fibrosis and Staphylococcal infections $[4,5,56,57]$, which pose significant challenges for antibiofilm drug efficacy $[2,3]$.

CAT-NP is also a sustainable material that can be synthesized at low cost on large scale, while $\mathrm{H}_{2} \mathrm{O}_{2}$ is a readily available and clinically used [27]. The flexibility of CAT-NP chemistry allows the production of new nanoparticle size and shapes as well as different coatings (e.g. dextrans) that may further improve biofilm localization. We plan future studies to examine the roles of CAT-NP physical characteristics on biofilm penetration/retention, in situ catalysis and anti-biofilm activity. For example, it is possible that decreasing size may enhance activity due to greater surface area to volume ratio combined with enhanced penetration, while identification of optimal charge characteristics may also prove important to minimize off-target binding effects. It is important to note that we used low concentrations of $\mathrm{H}_{2} \mathrm{O}_{2}(1 \%)$, which is several fold-less than those currently used in the over-the-counter products, which ranges from 3-10\%. The availability of these materials and CAT-NP chemical flexibility may facilitate translational research into dental applications, and lead to enhanced formulations with improved efficacy with under 1-minute topical treatments. For example, toothpaste or mouthrinse containers with separate chambers can keep CAT-NP and $\mathrm{H}_{2} \mathrm{O}_{2}$ separated in storage, but allowing mixing at the time of rising or brushing. Altogether, the results from this work may lead to a feasible new antiplaque and anti-caries therapeutics platform for topical use. 


\section{Acknowledgements}

The authors thank Dr. Andrew Tsourkas (Penn Engineering), Dr. William H. Bowen (University of Rochester) and Dr. Kenneth M. Yamada (NIDCR, NIH) for critically reading the manuscript and Dr. Faizan Alawi (Director, Penn Oral Pathology Labs) for histopathological analyses of the oral tissues. The authors are also grateful to Dr. M. Benakanakere for providing the primary human gingival epithelial cells for the supplementary data on evaluation of nanoparticles cell toxicity in vitro. L.G. and D.P.C. were supported by International Association for Dental Research / GlaxoSmithKline Innovation in Oral Care Award. H.K. was supported by the National Science Foundation (NSF) EFRI-1137186 and R01 DE018023. We are grateful for support from the University of Pennsylvania Research Foundation. Imaging experiments were performed in the PennVet Imaging Core Facility on instrumentation supported by NIH S10RR027128, the School of Veterinary Medicine, the University of Pennsylvania, and the Commonwealth of Pennsylvania.

\section{Competing financial interests}

The authors declare no competing financial interests. 


\section{References}

[1] L. Hall-Stoodley, J.W. Costerton, P. Stoodley. Bacterial biofilms: from the natural environment to infectious diseases. Nature Reviews Microbiology 2(2) (2004) 95-108.

[2] H.C. Flemming, J. Wingender. The biofilm matrix. Nature Reviews Microbiology 8(9) (2010) 623-33.

[3] D. Lebeaux, J.M. Ghigo, C. Beloin. Biofilm-related infections: bridging the gap between clinical management and fundamental aspects of recalcitrance toward antibiotics. Microbiology and Molecular Biology Reviews 78(3) (2014) 510-43.

[4] H. Koo, M.L. Falsetta, M.I. Klein. The exopolysaccharide matrix: a virulence determinant of cariogenic biofilm. Journal of Dental Research 92(12) (2013) 1065-73.

[5] N. Takahashi, B. Nyvad. The role of bacteria in the caries process: ecological perspectives. Journal of Dental Research 90(3) (2011) 294-303.

[6] T. Beikler, T.F. Flemmig. Oral biofilm-associated diseases: trends and implications for quality of life, systemic health and expenditures. Periodontology 2000 55(1) (2011) 87-103. [7] J. Xiao, M.I. Klein, M.L. Falsetta, B. Lu, C.M. Delahunty, J.R. Yates, 3rd, A. Heydorn, H. Koo. The exopolysaccharide matrix modulates the interaction between $3 \mathrm{D}$ architecture and virulence of a mixed-species oral biofilm. PLoS Pathogens 8(4) (2012) e1002623.

[8] M. Hannig, C. Hannig. Nanomaterials in preventive dentistry. Nature Nanotechnology 5(8) (2010) 565-9.

[9] R.P. Allaker, K. Memarzadeh. Nanoparticles and the control of oral infections. International Journal of Antimicrobial Agents 43(2) (2014) 95-104.

[10] J. Autio-Gold. The role of chlorhexidine in caries prevention. Operative Dentistry 33(6) (2008) 710-6. 
[11] C.G. Jones. Chlorhexidine: is it still the gold standard? Periodontology 200015 (1997) 5562.

[12] A. Besinis, T. De Peralta, C.J. Tredwin, R.D. Handy. Review of nanomaterials in dentistry: interactions with the oral microenvironment, clinical applications, hazards, and benefits. ACS Nano 9(3) (2015) 2255-89.

[13] C. Dawes, J.M. ten Cate. International collaborative research on fluoride. Journal of Dental Research 79(4) (2000) 893-904.

[14] H. Koo. Strategies to enhance the biological effects of fluoride on dental biofilms. Advances in Dental Research 20(1) (2008) 17-21.

[15] J.D. Featherstone, S. Domejean. The role of remineralizing and anticaries agents in caries management. Advances in Dental Research 24(2) (2012) 28-31.

[16] L. Gao, J. Zhuang, L. Nie, J. Zhang, Y. Zhang, N. Gu, T. Wang, J. Feng, D. Yang, S. Perrett, X. Yan. Intrinsic peroxidase-like activity of ferromagnetic nanoparticles. Nature Nanotechnology 2(9) (2007) 577-83.

[17] H. Wei, E. Wang. Nanomaterials with enzyme-like characteristics (nanozymes): nextgeneration artificial enzymes. Chemical Society Reviews 42(14) (2013) 6060-93.

[18] Y. Lin, J. Ren, X. Qu. Catalytically active nanomaterials: a promising candidate for artificial enzymes. Accounts of Chemical Research 47(4) (2014) 1097-105.

[19] F. Natalio, R. Andre, A.F. Hartog, B. Stoll, K.P. Jochum, R. Wever, W. Tremel. Vanadium pentoxide nanoparticles mimic vanadium haloperoxidases and thwart biofilm formation. Nature Nanotechnology 7(8) (2012) 530-5.

[20] L.Z. Gao, X.Y. Yan. Discovery and Current Application of Nanozyme. Progress in Biochemistry and Biophysics 40(10) (2013) 892-902. 
[21] H. Wei, E. Wang. $\mathrm{Fe}_{3} \mathrm{O}_{4}$ magnetic nanoparticles as peroxidase mimetics and their applications in $\mathrm{H}_{2} \mathrm{O}_{2}$ and glucose detection. Analytical Chemistry 80(6) (2008) 2250-2254.

[22] S.H. Liu, F. Lu, R.M. Xing, J.J. Zhu. Structural Effects of $\mathrm{Fe}_{3} \mathrm{O}_{4}$ Nanocrystals on Peroxidase-Like Activity. Chemistry: A European Journal 17(2) (2011) 620-625.

[23] H. Wang, H. Jiang, S. Wang, W.B. Shi, J.C. He, H. Liu, Y.M. Huang. $\mathrm{Fe}_{3} \mathrm{O}_{4}-\mathrm{MWCNT}$ magnetic nanocomposites as efficient peroxidase mimic catalysts in a Fenton-like reaction for water purification without pH limitation. RSC Advances 4(86) (2014) 45809-45815.

[24] L. Wang, Y. Min, D. Xu, F. Yu, W. Zhou, A. Cuschieri. Membrane lipid peroxidation by the peroxidase-like activity of magnetite nanoparticles. Chemical Communications 50(76) (2014) 11147-50.

[25] R. Noyori, M. Aoki, K. Sato. Green oxidation with aqueous hydrogen peroxide. Chemical Communications (16) (2003) 1977-1986.

[26] T.F.C. Mah, G.A. O'Toole. Mechanisms of biofilm resistance to antimicrobial agents. Trends in Microbiology 9(1) (2001) 34-39.

[27] M.V. Marshall, L.P. Cancro, S.L. Fischman. Hydrogen peroxide: a review of its use in dentistry. Journal of Periodontology 66(9) (1995) 786-96.

[28] D.P. Cormode, B.L. Sanchez-Gaytan, A.J. Mieszawska, Z.A. Fayad, W.J.M. Mulder. Inorganic nanocrystals as contrast agents in MRI: synthesis, coating and introduction of multifunctionality. NMR in Biomedicine 26(7) (2013) 766-780.

[29] P.A. Jarzyna, T. Skajaa, A. Gianella, D.P. Cormode, D.D. Samber, S.D. Dickson, W. Chen, A.W. Griffioen, Z.A. Fayad, W.J.M. Mulder. Iron oxide core oil-in-water emulsions as a multifunctional nanoparticle platform for tumor targeting and imaging. Biomaterials 30(36) (2009) 6947-6954. 
[30] J.H. Lee, Y.M. Huh, Y. Jun, J. Seo, J. Jang, H.T. Song, S. Kim, E.J. Cho, H.G. Yoon, J.S.

Suh, J. Cheon. Artificially engineered magnetic nanoparticles for ultra-sensitive molecular imaging. Nature Medicine 13(1) (2007) 95-99.

[31] M.I. Klein, J. Xiao, A. Heydorn, H. Koo. An analytical tool-box for comprehensive biochemical, structural and transcriptome evaluation of oral biofilms mediated by mutans streptococci. The Journal of Visualized Experiments (47) (2011).

[32] M.L. Falsetta, M.I. Klein, P.M. Colonne, K. Scott-Anne, S. Gregoire, C.H. Pai, M.

Gonzalez-Begne, G. Watson, D.J. Krysan, W.H. Bowen, H. Koo. Symbiotic relationship between Streptococcus mutans and Candida albicans synergizes virulence of plaque biofilms in vivo. Infection and Immunity 82(5) (2014) 1968-1981.

[33] H. Koo, M.F. Hayacibara, B.D. Schobel, J.A. Cury, P.L. Rosalen, Y.K. Park, A.M. VaccaSmith, W.H. Bowen. Inhibition of Streptococcus mutans biofilm accumulation and polysaccharide production by apigenin and $t t$-farnesol. Journal of Antimicrobial and Chemotherapy 52(5) (2003) 782-789.

[34] M.I. Klein, K.M. Scott-Anne, S. Gregoire, P.L. Rosalen, H. Koo. Molecular approaches for viable bacterial population and transcriptional analyses in a rodent model of dental caries. Molecular Oral Microbiology 27(5) (2012) 350-361.

[35] B. Horev, M.I. Klein, G. Hwang, Y. Li, D. Kim, H. Koo, D.S.W. Benoit. pH-Activated nanoparticles for controlled topical delivery of farnesol to disrupt oral biofilm virulence. ACS Nano 9(3) (2015) 2390-2404.

[36] P.C. Naha, A.A. Zaki, E. Hecht, M. Chorny, P. Chhour, E. Blankemeyer, D.M. Yates, W.R. Witschey, H.I. Litt, A. Tsourkas, D.P. Cormode. Dextran coated bismuth-iron oxide nanohybrid 
contrast agents for computed tomography and magnetic resonance imaging. Journal of Materials Chemistry B, Materials for Biology and Medicine 2(46) (2014) 8239-8248.

[37] M.Y. Liao, C.H. Wu, P.S. Lai, J.S. Yu, H.P. Lin, T.M. Liu, C.C. Huang. Surface state mediated NIR two-photon fluorescence of iron oxides for nonlinear optical microscopy. Advanced Functional Materials 23(16) (2013) 2044-2051.

[38] P.C. Naha, P. Chhour, D.P. Cormode. Systematic in vitro toxicological screening of gold nanoparticles designed for nanomedicine applications. Toxicology in Vitro 29(7) (2015) 14451453.

[39] W.H. Bowen. Rodent model in caries research. Odontology 101(1) (2013) 9-14.

[40] H. Koo, B. Schobel, K. Scott-Anne, G. Watson, W.H. Bowen, J.A. Cury, P.L. Rosalen, Y.K. Park. Apigenin and $t$-farnesol with fluoride effects on $S$. mutans biofilms and dental caries. Journal of Dental Research 84(11) (2005) 1016-1020.

[41] W.H. Bowen. The Stephan Curve revisited. Odontology 101(1) (2013) 2-8.

[42] O. Fejerskov, A.A. Scheie, F. Manji. The effect of sucrose on plaque $\mathrm{pH}$ in the primary and permanent dentition of caries-inactive and -active Kenyan children. Journal of Dental Research 71(1) (1992) 25-31.

[43] L. Gao, K.M. Giglio, J.L. Nelson, H. Sondermann, A.J. Travis. Ferromagnetic nanoparticles with peroxidase-like activity enhance the cleavage of biological macromolecules for biofilm elimination. Nanoscale 6(5) (2014) 2588-93.

[44] W.H. Bowen, H. Koo. Biology of Streptococcus mutans-derived glucosyltransferases: role in extracellular matrix formation of cariogenic biofilms. Caries Research 45(1) (2011) 69-86. 
[45] P.L. Rosalen, S.K. Pearson, W.H. Bowen. Effects of copper, iron and fluoride cocrystallized with sugar on caries development and acid formation in deslivated rats. Archives of Oral Biology. 41(11) (1996) 1003-10.

[46] A.C.B. Delbem, K.M.R.P. Alves, K.T. Sassaki, J.C.S. Moraes. Effect of iron II on hydroxyapatite dissolution and precipitation in vitro. Caries Research 46(5) (2012) 481-487.

[47] K. Forier, K. Raemdonck, S.C. De Smedt, J. Demeester, T. Coenye, K. Braeckmans. Lipid and polymer nanoparticles for drug delivery to bacterial biofilms. Journal of Controlled Release 190 (2014) 607-623.

[48] S.X. Zhang, X.L. Zhao, H.Y. Niu, Y.L. Shi, Y.Q. Cai, G.B. Jiang. Superparamagnetic $\mathrm{Fe}_{3} \mathrm{O}_{4}$ nanoparticles as catalysts for the catalytic oxidation of phenolic and aniline compounds. Journal of Hazardous Materials 167(1-3) (2009) 560-566.

[49] X.C. Wu, Y. Zhang, T. Han, H.X. Wu, S.W. Guo, J.Y. Zhang. Composite of graphene quantum dots and $\mathrm{Fe}_{3} \mathrm{O}_{4}$ nanoparticles: peroxidase activity and application in phenolic compound removal. RSC Advances 4(7) (2014) 3299-3305.

[50] K.M.R.P. Alves, K.S. Franco, K.T. Sassaki, M.A.R. Buzalaf, A.C.B. Delbem. Effect of iron on enamel demineralization and remineralization in vitro. Archives of Oral Biology 56(11) (2011) 1192-1198.

[51] R. Shaoul, L. Gaitini, J. Kharouba, G. Darawshi, I. Maor, M. Somri. The association of childhood iron deficiency anaemia with severe dental caries. Acta Paediatrica 101(2) (2012) E76-E79.

[52] C. Corot, P. Robert, J.M. Idee, M. Port. Recent advances in iron oxide nanocrystal technology for medical imaging. Advanced Drug Delivery Reviews 58(14) (2006) 1471-504. 
[53] N. Lee, T. Hyeon. Designed synthesis of uniformly sized iron oxide nanoparticles for efficient magnetic resonance imaging contrast agents. Chemical Society Reviews 41(7) (2012) 2575-89.

[54] C. Kaittanis, T.M. Shaffer, A. Ogirala, S. Santra, J.M. Perez, G. Chiosis, Y. Li, L. Josephson, J. Grimm. Environment-responsive nanophores for therapy and treatment monitoring via molecular MRI quenching. Nature Communications 5 (2014) 3384.

[55] C. Contreras, M.D. Barnuevo, I. Guillen, A. Luque, E. Lazaro, J. Espadaler, J. LopezRoman, J.A. Villegas. Comparative study of the oral absorption of microencapsulated ferric saccharate and ferrous sulfate in humans. European Journal of Nutrition 53(2) (2014) 567-74. [56] R.C. Mercier, C. Stumpo, M.J. Rybak. Effect of growth phase and $\mathrm{pH}$ on the in vitro activity of a new glycopeptide, oritavancin (LY333328), against Staphylococcus aureus and Enterococcus faecium. The Journal of Antimicrobial Chemotherapy 50(1) (2002) 19-24. [57] J. Poschet, E. Perkett, V. Deretic. Hyperacidification in cystic fibrosis: links with lung disease and new prospects for treatment. Trends in Molecular Medicine 8(11) (2002) 512-9. 


\section{Figure legends}

Figure 1. CAT-NP retention and spatial distribution within 3D biofilm structure. a, Scanning electron microscopy (SEM) of the morphology of untreated biofilm and (b) treated with CAT-NP (CAT-NP bound; see arrows). Magnified view of CAT-NP in the selected area (b1). SEM/EDS images showing iron (pink) distribution on biofilms (b2). c, CAT-NP bound on biofilm as determined by measuring iron amounts with ICP-MS. d, 3D architecture of untreated biofilm. e, Spatial distribution of CAT-NP in treated biofilm: f, CAT-NP (white); $\mathbf{g}$, bacteria (green); h, EPS (red) are observed with confocal microscopy. i, Cross-sectional merged images of top and middle areas of the biofilm. $\mathbf{j}$, Orthogonal distribution of CAT-NP, and (k) bacteria and EPS across biofilm thickness

Figure 2. CAT-NP activity within biofilms with $\mathrm{pH}$ dependent catalysis in situ. a, Catalytic activity of CAT-NP adsorbed within biofilms. Inset: photographic images of CAT-NP treated biofilm before and after exposure to $\mathrm{H}_{2} \mathrm{O}_{2}$ and TMB (the blue color indicates free-radical generation via $\mathrm{H}_{2} \mathrm{O}_{2}$ catalysis in situ). b, Catalytic activity of CAT-NP $\left(0.5 \mathrm{mg} \mathrm{ml}^{-1}\right)$ treated biofilms at different $\mathrm{pH}$. The difference of absorbance values between $2 \mathrm{a}$ and $2 \mathrm{~b}$ is due to different incubation time used for each experiment. For figure $2 \mathrm{a}$, we conducted the incubation with $\mathrm{H}_{2} \mathrm{O}_{2}$ and TMB for 30 min to allow all samples generate signals, particularly for those treated with low CAT-NP concentration. For Figure $2 \mathrm{~b}$ (biofilms treated with $0.5 \mathrm{mg} \mathrm{ml}^{-1} \mathrm{CAT}$ $\mathrm{NP}$ ), the activity was determined using the standard 5 min incubation with $\mathrm{H}_{2} \mathrm{O}_{2}$ and TMB. 
Figure 3. Bacterial killing, EPS degradation and biofilm disruption by the combination of CAT-NP and $\mathrm{H}_{2} \mathrm{O}_{2}$. a, Viability of $S$. mutans within CAT-NP treated-biofilms 5 min after $\mathrm{H}_{2} \mathrm{O}_{2}$ exposure. b, EPS degradation within biofilm 30 min after $\mathrm{H}_{2} \mathrm{O}_{2}$ exposure. c, Degradation of insoluble glucans produced by GtfB and soluble glucans from GtfD. Data are shown as mean \pm s.d. $* P \leq 0.001$ (vs. control).

\author{
Figure 4. Dynamics of biofilm disruption after topical treatments with $\mathrm{CAT}-\mathrm{NP}+\mathrm{H}_{2} \mathrm{O}_{2} \cdot$ a. \\ Confocal microscopy images at different time points. Biofilms received topical treatment by \\ CAT-NP followed immediately by $\mathrm{H}_{2} \mathrm{O}_{2}$ exposure $\left(\mathrm{CAT}-\mathrm{NP}+\mathrm{H}_{2} \mathrm{O}_{2}\right.$ ) or sodium acetate buffer \\ (CAT-NP alone) twice daily. For $\mathrm{H}_{2} \mathrm{O}_{2}$, biofilms were treated with sodium acetate buffer \\ followed immediately by $\mathrm{H}_{2} \mathrm{O}_{2}$ exposure. The control group consisted of biofilms treated with \\ buffer only. Bacterial cells were stained with SYTO 9 (in green) and EPS were labeled with
} Alexa Fluor 647 (in red). b. COMSTAT analysis of total, cell and EPS biovolume for biofilm at 43h. Data are shown as mean \pm s.d. $* P \leq 0.001$ (vs. control).

Figure 5. Protection against development of carious lesions by CAT-NP/ $/ \mathrm{H}_{2} \mathrm{O}_{2}$ treatment. a, Images of teeth from rats treated as noted. Green arrows indicate initial lesion formation where areas of the enamel is demineralized and become white; blue arrows show moderate carious lesions where areas of enamel are white-opaque or damaged. In some areas, the enamel is eroded leading to cavitation, which are the most severe carious lesions (red arrows). Caries scores are recorded as stages and extent of carious lesion severity according to Larson's modification of 
Keyes' scoring system: b, Initial lesion (surface enamel white); c, moderate lesion (enamel white-opaque) and extensive (cavitation with enamel eroded and underlying dentin exposed). Data are shown as mean \pm s.d. $* P \leq 0.001$ (vs. control); $* * P \leq 0.05$ (vs. control); $\delta$ indicates non-detected.

Figure 6. CAT-NP reduces sHA acid-dissolution. a, Amount of iron released from CAT-NP after incubation at $\mathrm{pH} 4$ or $\mathrm{pH} 7$ via colorimetric assay (Iron Assay Kit, Sigma-Aldrich). b, Amount of remaining sHA after acid-dissolution with or without CAT-NP. c, Optical microscopy (OM) and scanning electron microscopy (SEM) imaging of untreated sHA beads ( 80 $\mu \mathrm{m}$ diameter), sHA beads in acidic buffer (pH4.5), and sHA beads with CAT-NP in acidic buffer. The data are depicted as mean \pm s.d.

Figure 7. Schematics of biofilm disruption under acidic conditions by CAT-NP/ $/ \mathrm{H}_{2} \mathrm{O}_{2}$ in situ . 

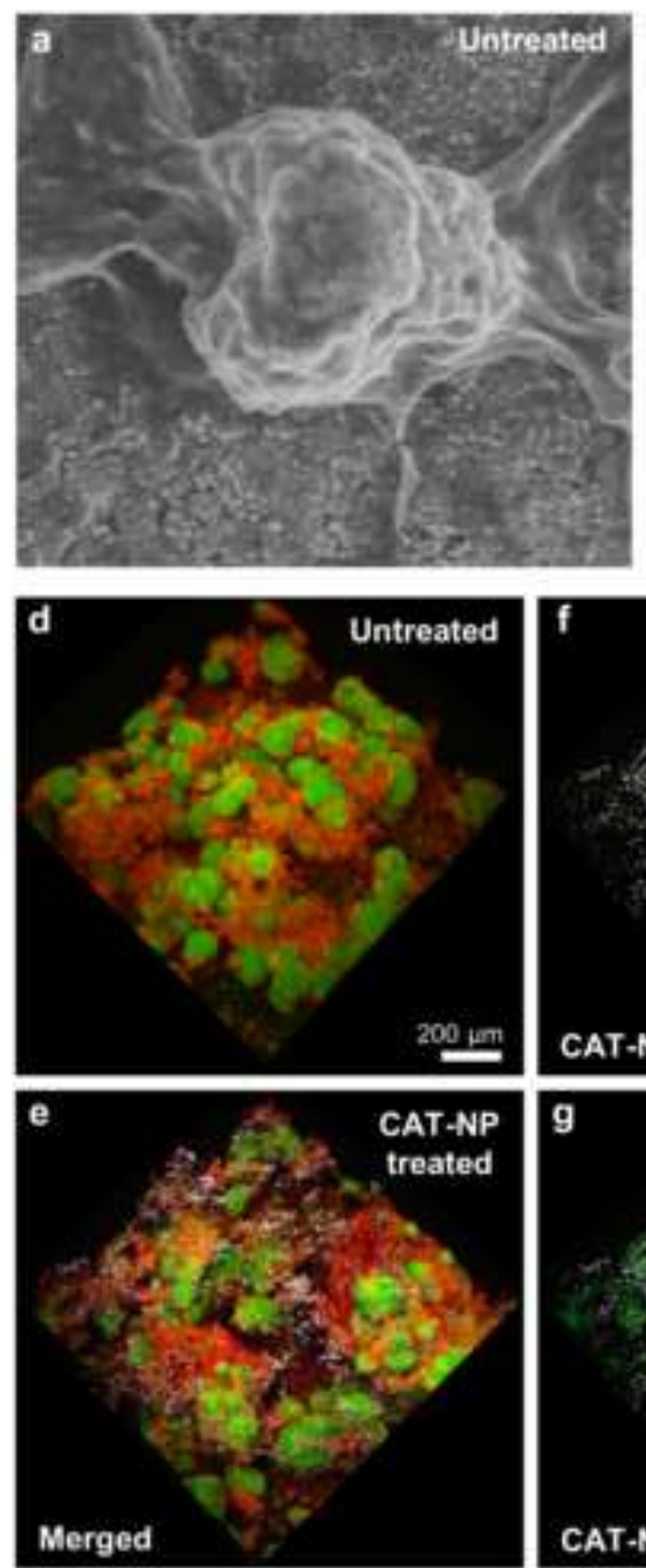
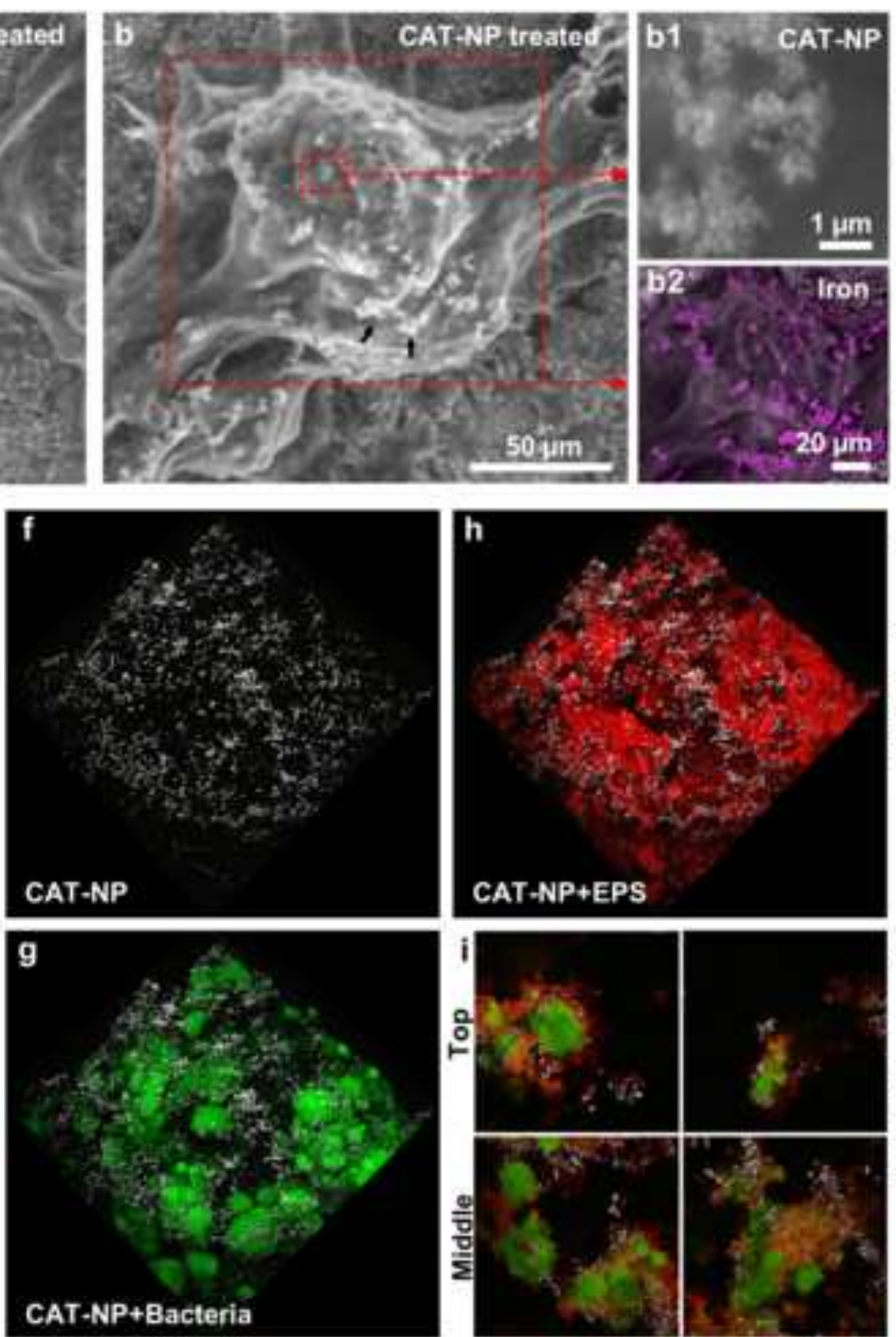
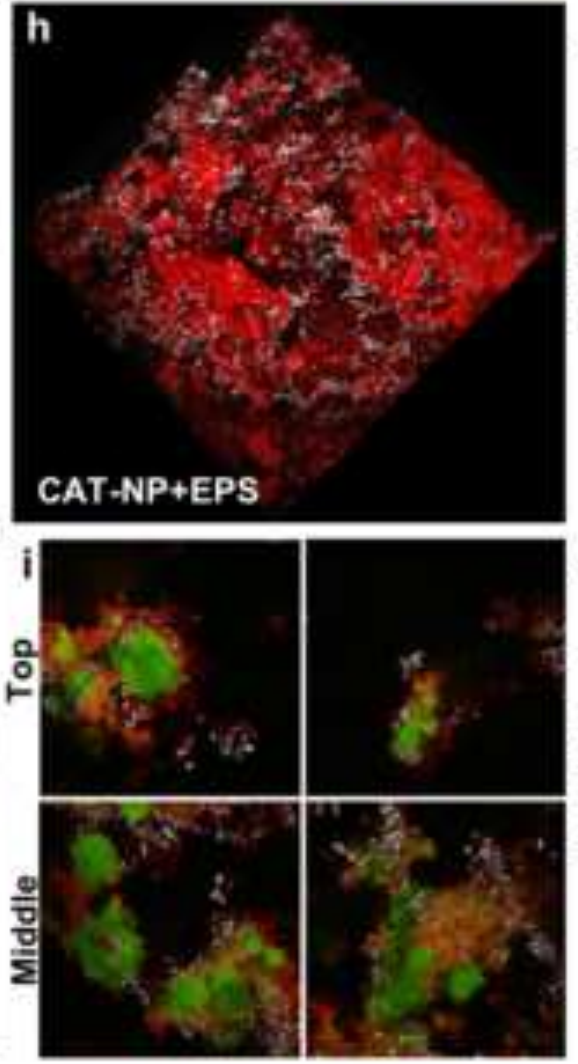
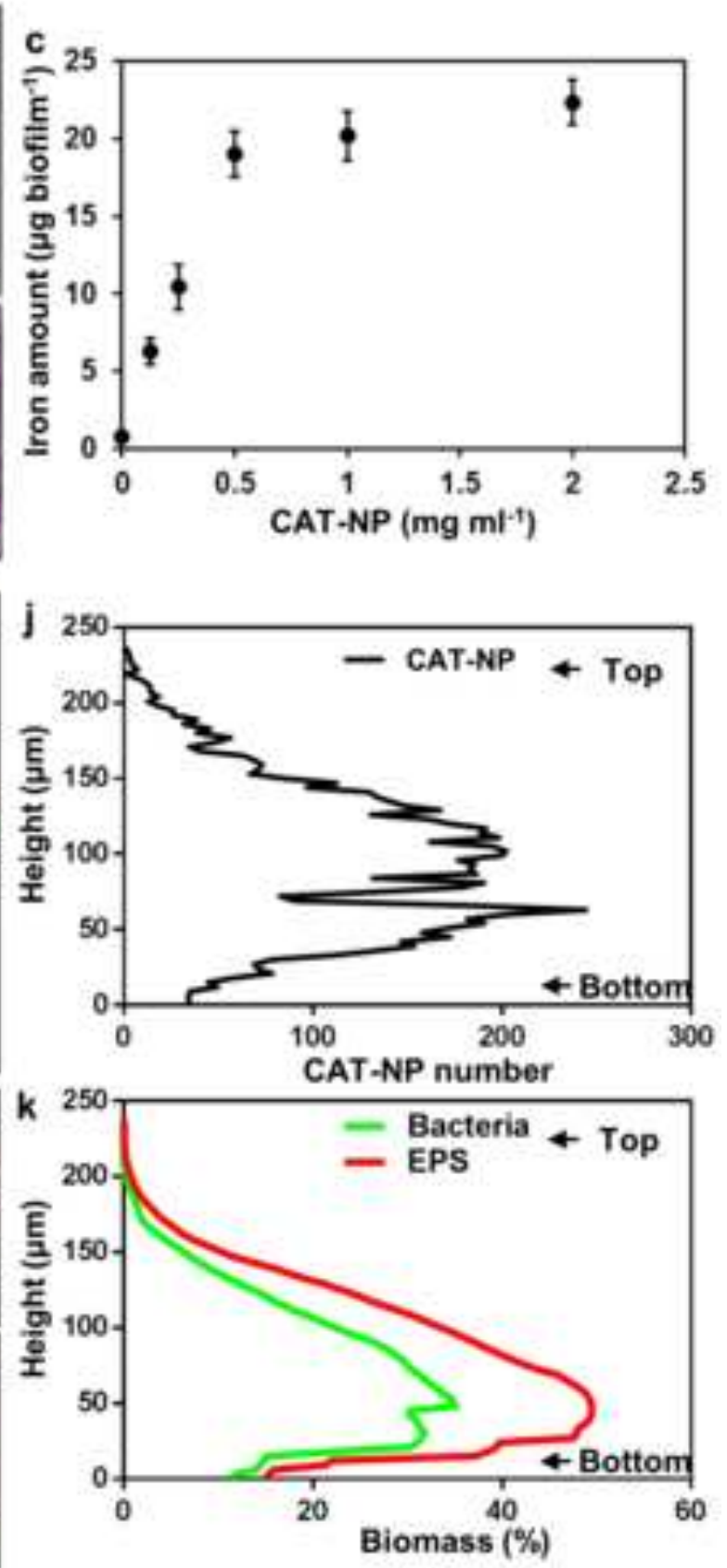

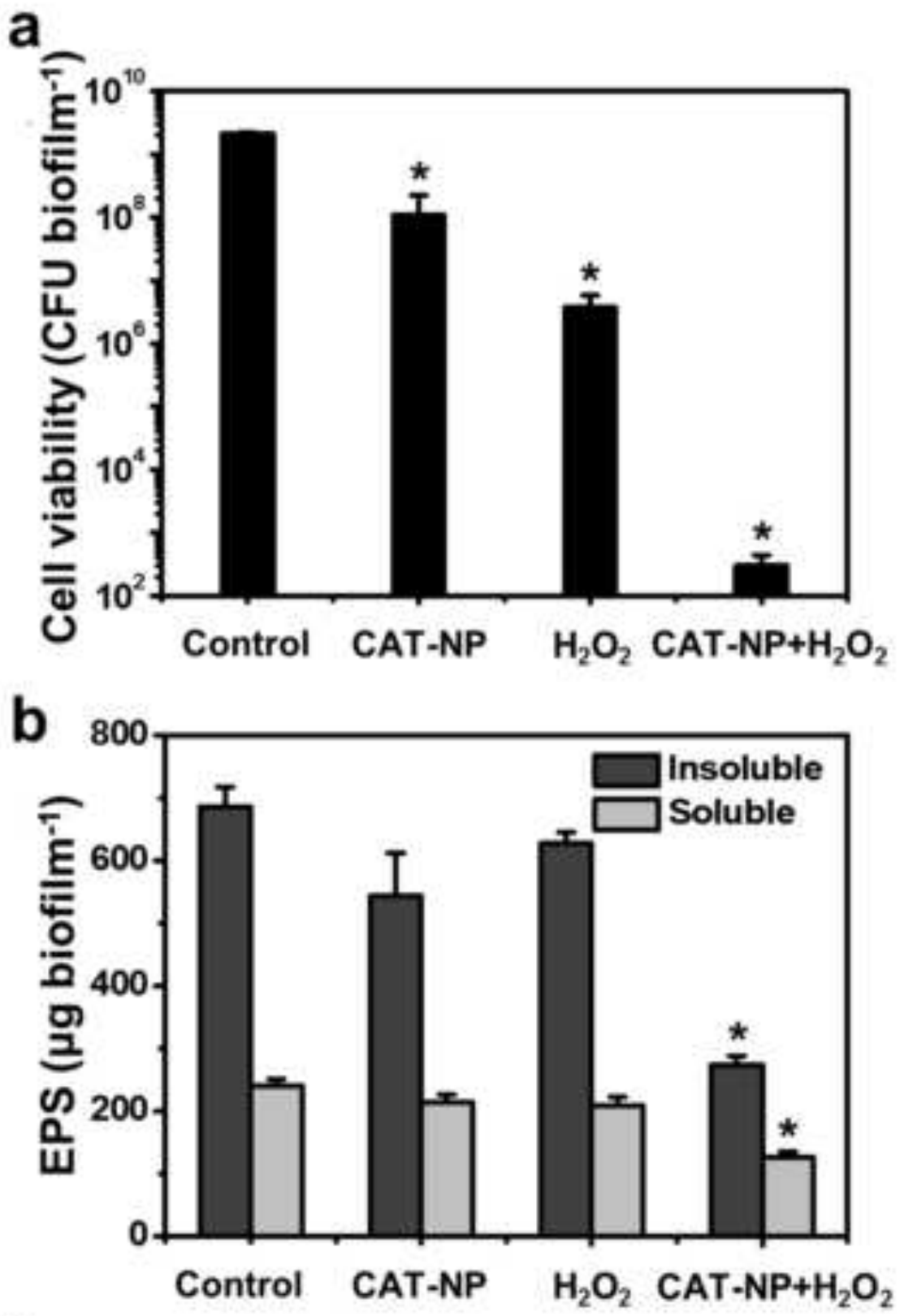

C

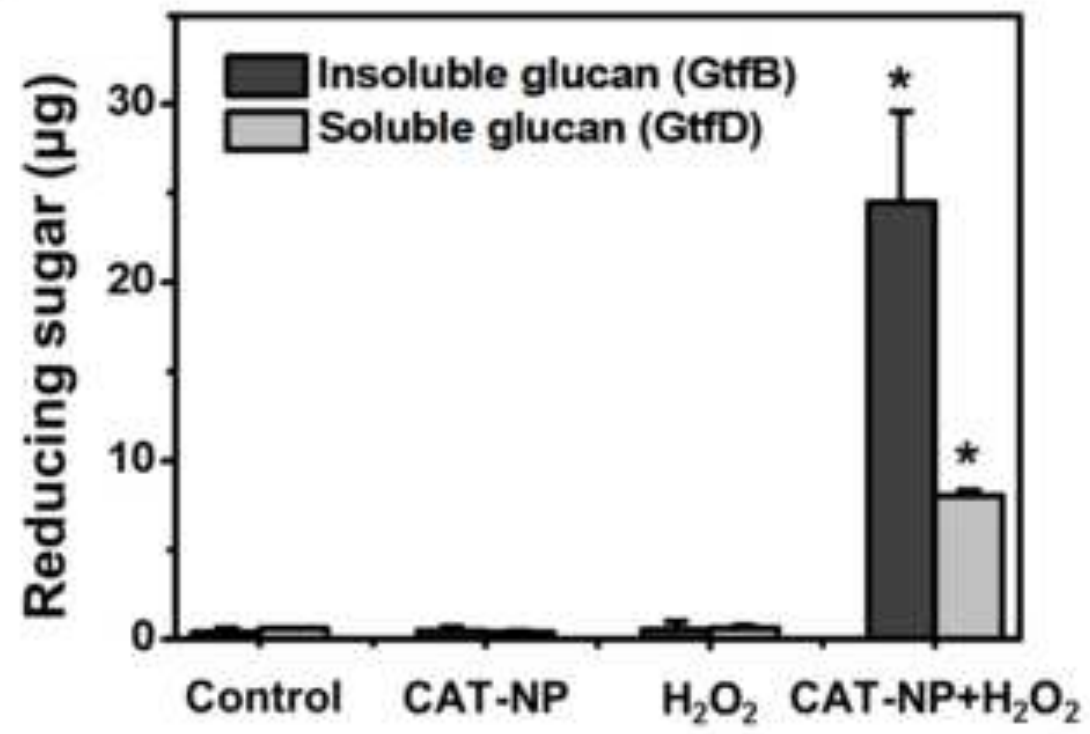


a
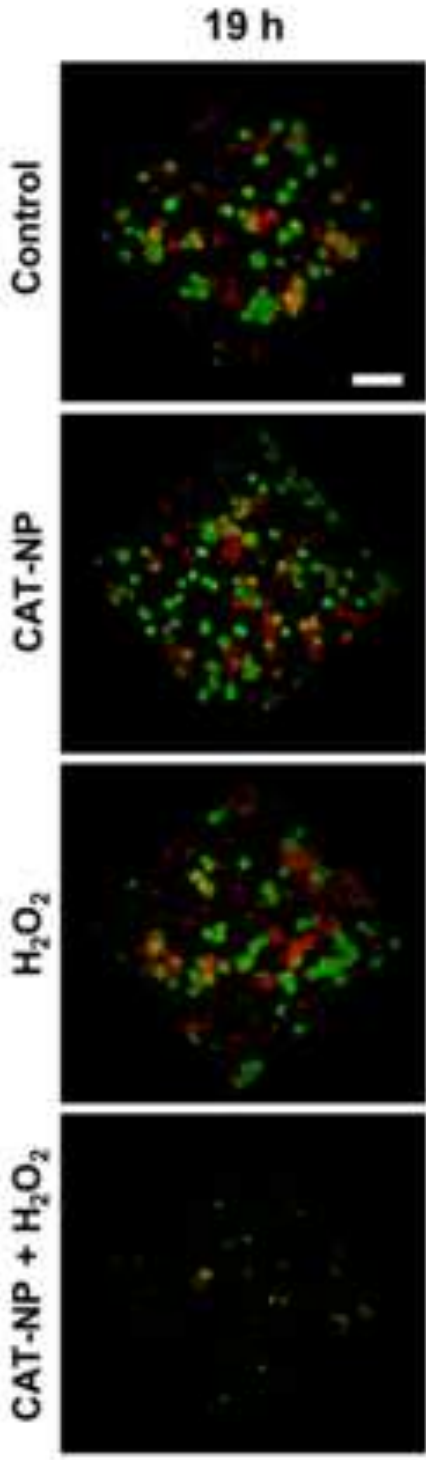

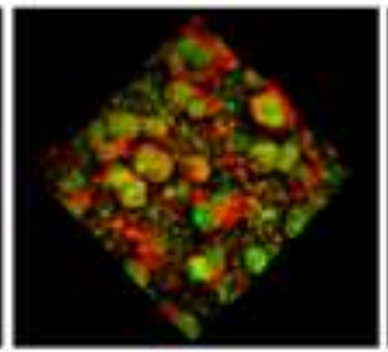

$29 \mathrm{~h}$
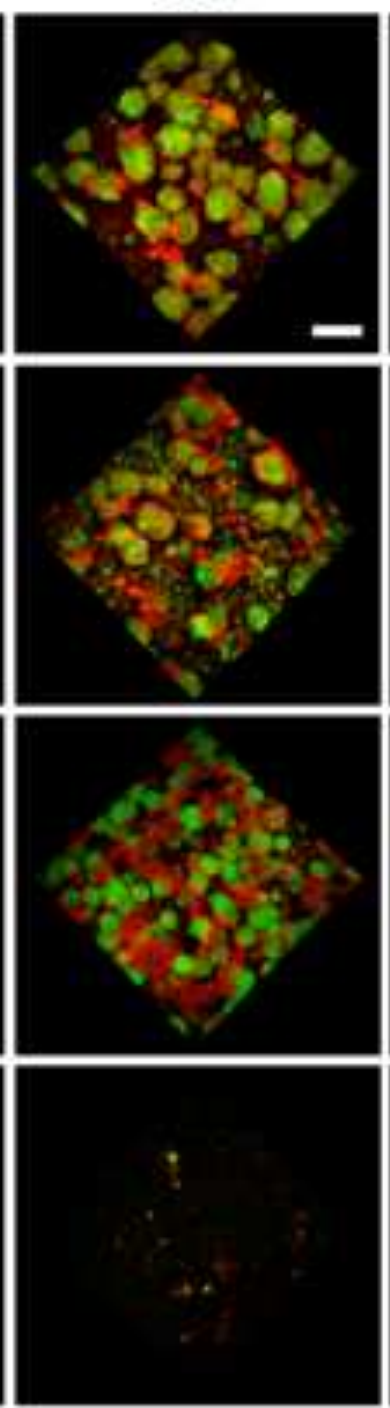

$43 \mathrm{~h}$
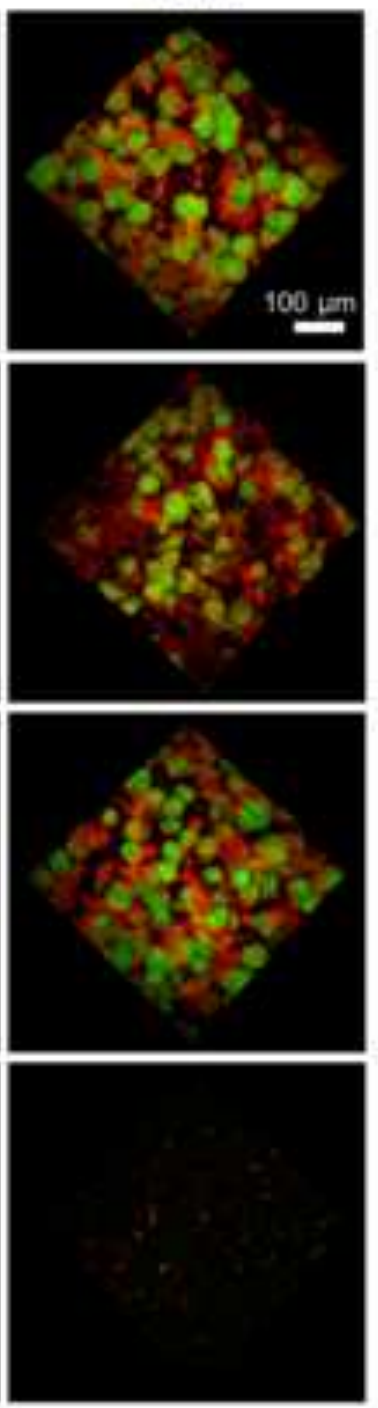

b

COMSTAT Analysis

\begin{tabular}{lccc}
\hline Biofilm 43h & $\begin{array}{c}\text { Total Biovolume } \\
\left(\mu \mathrm{m}^{3} / \mu^{2}\right)\end{array}$ & $\begin{array}{c}\text { Cell Biovolume } \\
\left(\mu \mathrm{m}^{3} / \mu \mathrm{m}^{2}\right)\end{array}$ & $\begin{array}{c}\text { EPS Biovolume } \\
\left(\mu \mathrm{m}^{\left.3 / \mu m^{2}\right)}\right.\end{array}$ \\
\hline Control & $204.2 \pm 17.4$ & $98.9 \pm 6.8$ & $105.3 \pm 11.1$ \\
CAT-NP & $229.5 \pm 11.3$ & $113.1 \pm 12.3$ & $116.5 \pm 6.3$ \\
$\mathrm{H}_{2} \mathrm{O}_{2}$ & $194.8 \pm 7.8$ & $89.8 \pm 6.4$ & $105.0 \pm 2.3$ \\
CAT-NP+ $\mathrm{H}_{2} \mathrm{O}_{2}$ & $2.6 \pm 0.2^{*}$ & $1.7 \pm 0.1^{*}$ & $0.9 \pm 0.3^{*}$ \\
\hline
\end{tabular}


a
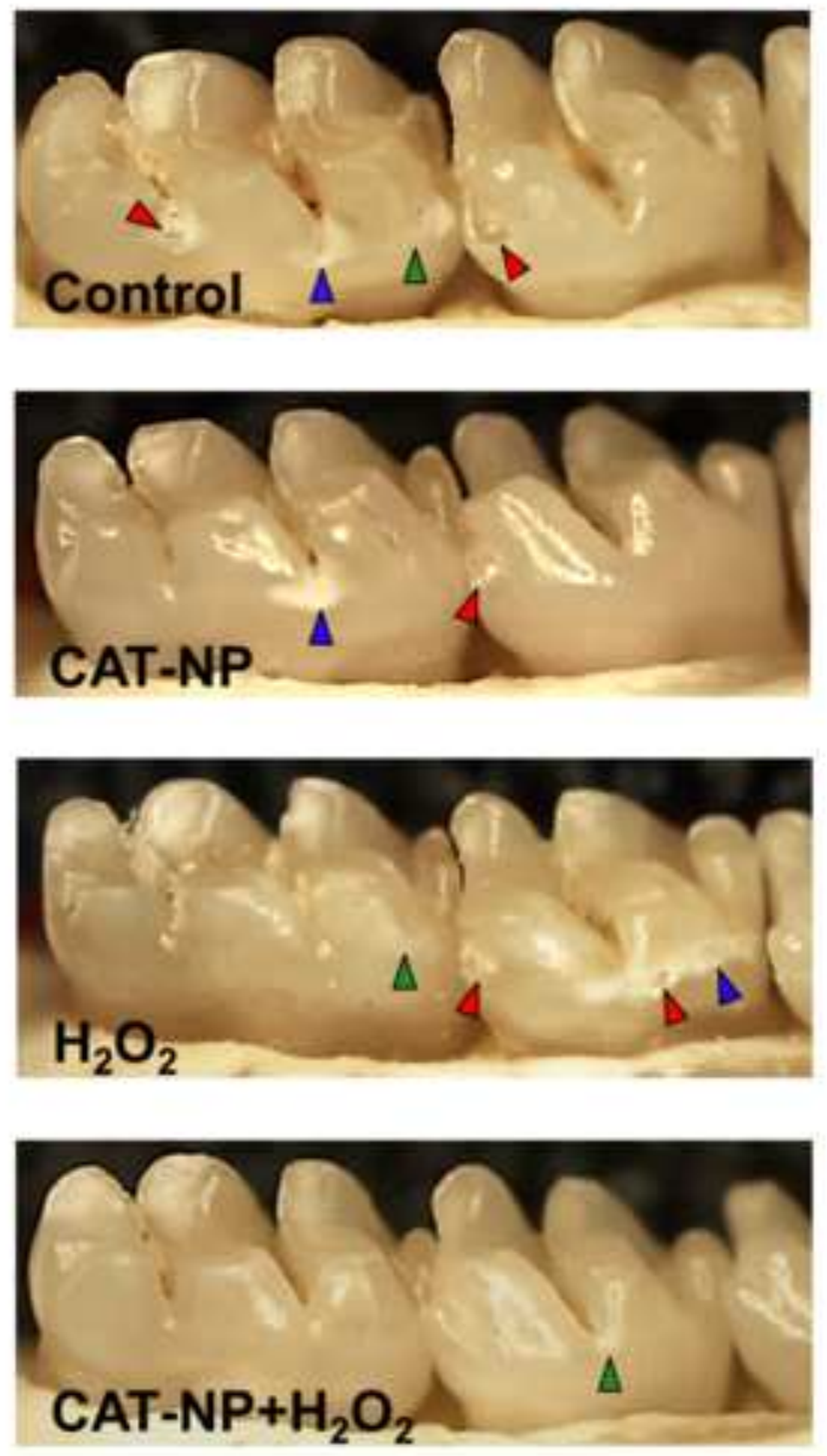

b
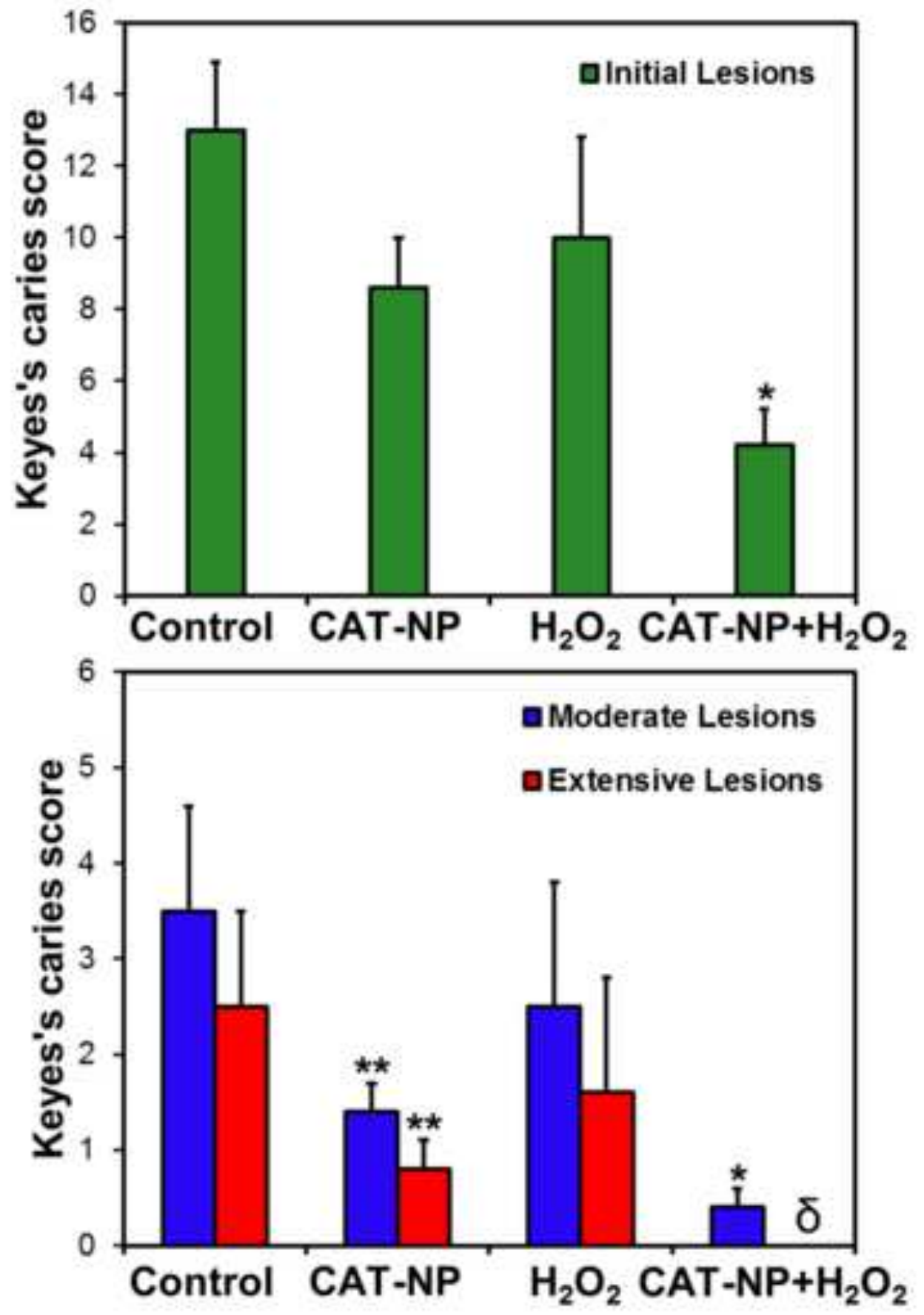

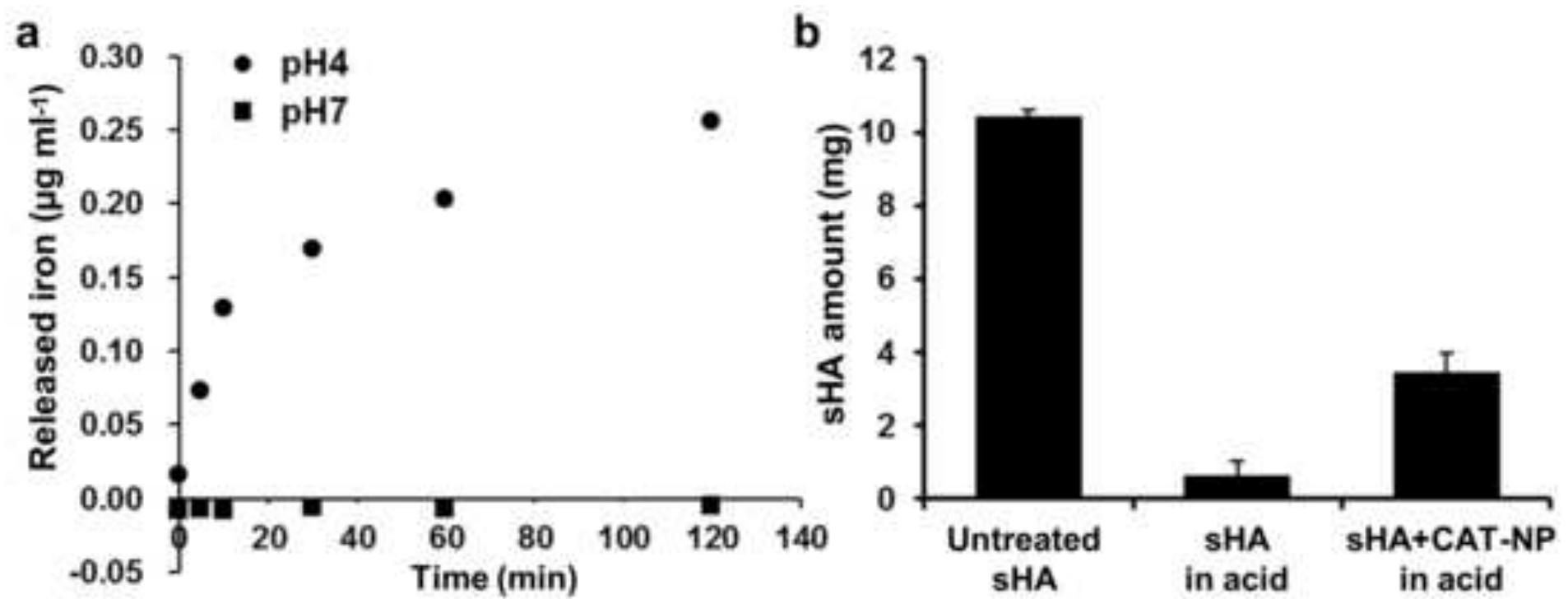

C

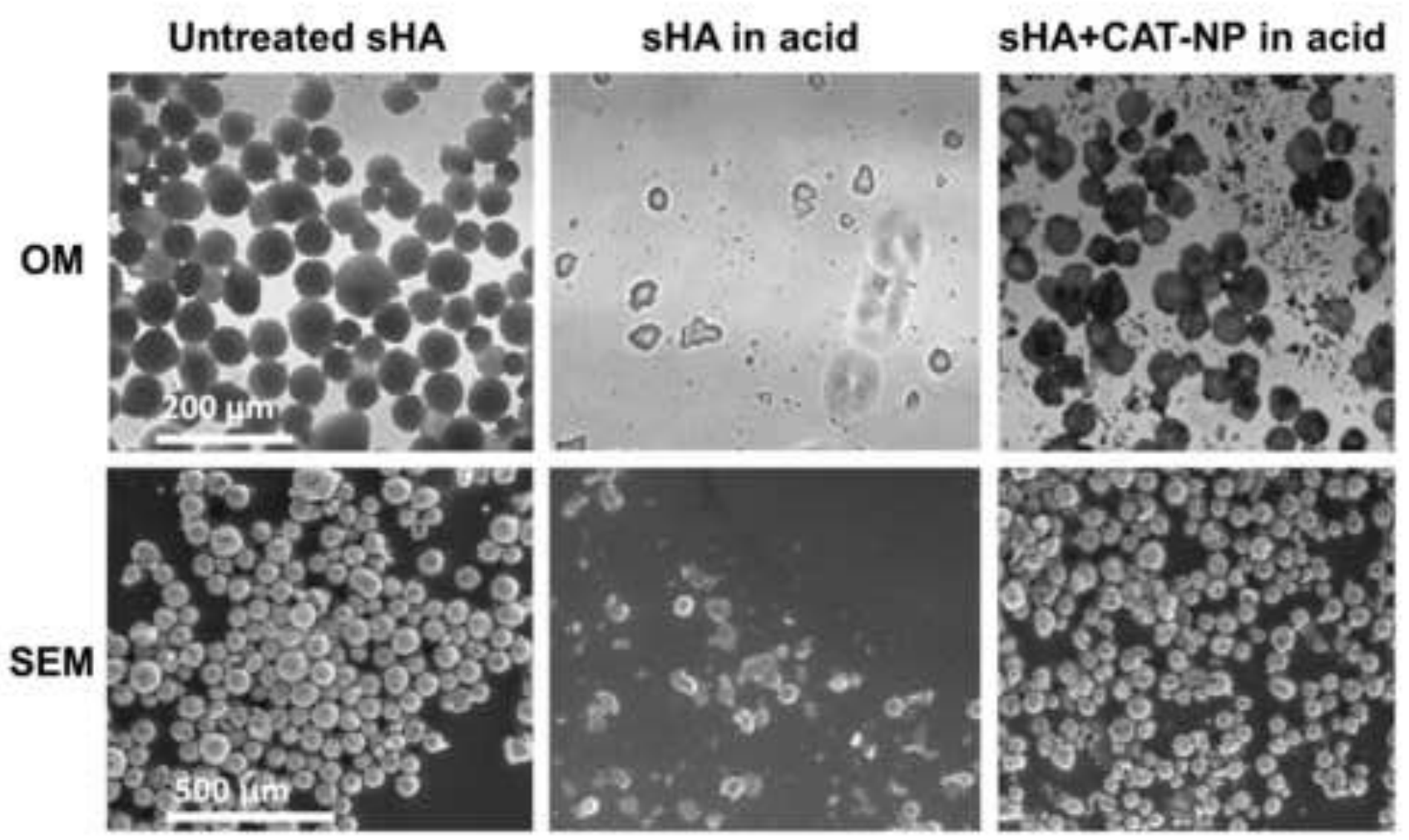


